NBER WORKING PAPER SERIES

\title{
INEQUALITY TRENDS FOR GERMANY IN THE LAST TWO DECADES: A TALE OF TWO COUNTRIES
}

\author{
Nicola Fuchs-Schündeln \\ Dirk Krueger \\ Mathias Sommer \\ Working Paper 15059 \\ http://www.nber.org/papers/w15059
}

\author{
NATIONAL BUREAU OF ECONOMIC RESEARCH \\ 1050 Massachusetts Avenue \\ Cambridge, MA 02138 \\ June 2009
}

We thank Michael Ziegelmeyer for invaluable help with the EVS data, Fatih Karahan, Serdar Ozkan, and Carolin Pflueger for excellent research assistantship, and participants at the Philadelphia conference on Heterogeneity in Macroeconomics for useful comments. Dirk Krueger acknowledges financial support from the NSF under grant SES-0820494. The views expressed herein are those of the author(s) and do not necessarily reflect the views of the National Bureau of Economic Research.

NBER working papers are circulated for discussion and comment purposes. They have not been peerreviewed or been subject to the review by the NBER Board of Directors that accompanies official NBER publications.

(C) 2009 by Nicola Fuchs-Schündeln, Dirk Krueger, and Mathias Sommer. All rights reserved. Short sections of text, not to exceed two paragraphs, may be quoted without explicit permission provided that full credit, including $\odot$ notice, is given to the source. 
Inequality Trends for Germany in the Last Two Decades: A Tale of Two Countries

Nicola Fuchs-Schündeln, Dirk Krueger, and Mathias Sommer

NBER Working Paper No. 15059

June 2009

JEL No. D31,D33,E24

\begin{abstract}
$\underline{\text { ABSTRACT }}$
In this paper we first document inequality trends in wages, hours worked, earnings, consumption, and wealth for Germany from the last twenty years. We generally find that inequality was relatively stable in West Germany until the German unification (which happened politically in 1990 and in our data in 1991), and then trended upwards for wages and market incomes, especially after about 1998. Disposable income and consumption, on the other hand, display only a modest increase in inequality over the same period. These trends occured against the backdrop of lower trend growth of earnings, incomes and consumption in the 1990s relative to the 1980s. In the second part of the paper we further analyze the differences between East and West Germans in terms of the evolution of levels and inequality of wages, income, and consumption.
\end{abstract}

Nicola Fuchs-Schündeln

Department of Economics

Harvard University

Littauer 212

1875 Cambridge Street

Cambridge, MA 02138

and NBER

nfuchs@harvard.edu

Dirk Krueger

Department of Economics

University of Pennsylvania

3718 Locust Walk

Philadelphia, PA 19104

and NBER

dkrueger@econ.upenn.edu
Mathias Sommer

MEA, University of Mannheim

L 13, 17

68131 Mannueim, Germany

mathias.sommer@gmx.net 
Keywords: Inequality, German Unification

JEL Classification: D31, D33, E24

\section{Introduction}

In this paper we document inequality trends in wages, hours worked, earnings, consumption, and wealth for Germany from the last two decades, using household-level data from the German Socio-Economic Panel (GSOEP) study and the Income and Expenditure Survey (EVS). The objective of this paper is two-fold. First, our work is part of a larger research project that attempts to document Cross-Sectional Facts for Macroeconomists for a variety of countries in a uniform way (see Krueger, Perri, Pistaferri and Violante, 2008), and many of the choices concerning data, sample selection and the choice of what facts to present are motivated by common guidelines across countries. But second, since the German case is special because of the unique event of the German Reunification in 1990 (1991 in most of our data) we analyze in greater detail the impact on overall wage, income, consumption and wealth inequality by East Germany (officially, the German Democratic Republic, GDR) joining West Germany (officially, the Federal Republic of Germany, FRG) roughly in the middle of our sample period.

Summarizing our main results, we find that, roughly speaking, inequality remained constant in West Germany until the German unification in 1990 (and might even have slightly declined), and then trended upwards. We also note, however, that income measures that include public redistribution through taxes and transfers display significantly lower increases in inequality (if any) than pre-tax/transfer income measures. Consumption inequality mirrors this trend in disposable income inequality (or the lack thereof). These inequality trends have to be interpreted against the backdrop of significantly lower trend growth of earnings and incomes in the 1990s relative to the 1980s.

Our analysis of economic inequality and its trends in Germany is related to a growing number of studies that use household micro data from the GSOEP or the EVS to document how the cross-sectional distribution of wages or income has evolved in the last 25 years. For wages, Dustmann et al. (2007) use official social security records to document trends in wage dispersion in the 1980s and 1990s. They find that in the 1980s wage dispersion rose only at the top of the distribution, while in the 1990s it also rose at the bottom of the distribution. While our GSOEP data likely misses some of the wage 
observations at the very top and thus it is not surprising that we do not observe the increase in wage inequality prior to German unification, our analysis exhibits the same increase in wage inequality in the 1990s that they find.

Bach et al. (2007) integrate GSOEP and tax data to document trends in inequality in market incomes for 1992 to 2001. They find that inequality, as measured by the Gini, increases moderately. Behind this trend in the Gini is hidden a substantial decline in median income and a strong increase in income at the top $0.1 \%$ of the distribution. Furthermore, households at the top of the distribution obtain an increasing share of their income through labor income (although capital income still dominates as a source of overall income). While our focus on GSOEP (and EVS) data does not permit us to obtain a precise picture of the very top of the income distribution, the trends in pre-tax income inequality we document are consistent with their findings.

Biewen (2000) finds that inequality in equivalized (by household size) disposable income has remained stable for West German households between 1984 and 1996, and a strong increase in inequality among East German households between 1990 and 1996. In section 7 of our paper we decompose inequality trends in Germany into its regional (East and West) components and obtain very similar results for disposable income and other economic variables of interest. ${ }^{1}$

For wealth, Hauser and Stein (2003) use the EVS from 1973 to 1998 to document inequality levels and trends in West German household wealth, composed of real estate, consumer durables and financial assets at market values. They document somewhat of a decline in wealth inequality (as measured by the Gini coefficient) between 1973 and 1988, and a further decline between 1988 and 1993. Wealth inequality in 1998 is marginally higher than in 1993. Our most comprehensive measure of wealth, which also includes financial wealth and real estate (but not other consumer durables) in contrast displays somewhat of an increase in inequality, also measured by the Gini, for the years 1978 to 1988. For the period between 1993 and 1998 we measure the overall wealth Gini as essentially unchanged, as they do. However, we do not find a decline in wealth inequality that they display for their wealth

\footnotetext{
${ }^{1}$ Frick and Grabka (2008) as well as Becker et al. (2003) analyze the evolution of Gini coefficients of disposable income in Germany. Frick and Grabka (2008) report a somewhat larger increase in the Gini since 1998 than we find, a discrepancy that can be explained by the differences in sample definitions and equivalization schemes employed in this paper relative to theirs. In fact, if we use their definitions we obtain very similar results to theirs.
} 
measure between 1978 and $1988 .^{2}$

Finally, Schwarze (1996) decomposes the change in income inequality directly after the German reunification into the parts attributable to changes in inequality in the East, inequality in the West, and changes in inequality between both regions. In the second part of the paper we employ a similar decomposition analysis (although we use a different, linearly decomposable inequality statistic, the variance of logs, which is also our primary statistic used in other parts of the paper) for a wider range of economic variables and a longer time horizon to document differential trends of inequality in the former Eastern and the former Western parts of the country.

The paper is organized as follows. In the next section we briefly describe the historical context and the macroeconomic environment during our sample period. We also provide a brief overview over the two key data sources underlying the facts presented here. In section 3 we then discuss trends in the levels of average wages, income, and consumption from our micro data, and compare these trends to the corresponding figures from the German National Income and Product Accounts (NIPA). Section 4 is devoted to our main object of interest, namely the evolution of inequality in Germany over the last two decades. In section 5 we display how inequality of wages, earnings, and consumption in Germany evolve over the life cycle. We make use of the GSOEP panel dimension to estimate, in section 6, a parsimonious stochastic wage and earnings process for Germany that can be used as an important input in structural macroeconomic models with household heterogeneity. Finally, in section 7 we pay tribute to the unique event of the German Reunification and carry out a more detailed analysis of how the inequality trends displayed in section 4 have been affected (in a statistical sense) by this event. Section 8 concludes.

\footnotetext{
${ }^{2}$ Furthermore, the increase in wealth inequality we document throughout the sample period is significantly larger when we restrict attention to financial wealth only. The differences in findings are mainly attributed to the fact that our wealth measure differs from theirs and that they do not employ as restrictive a sample selection criterion as we do (both our choices were made in order to conform to the general data guidelines for the overall project).
} 


\section{Historical Background and Data Situation}

\subsection{Macroeconomic and Institutional Conditions Dur- ing the Sample Period}

Within the period for which we have data to document inequality in Germany falls the single most important political and economic event of post WWII Germany, the German unification. The decade 1980-90 prior to unification was characterized by what Giersch, Paque and Schmieding in 1992 called the Fading Miracle. These authors document that relative to the post WWII period growth in Germany had slowed down. From the perspective of 15 years later, however, the years prior to German unification look good (judging by the metric of economic growth) relative to what was about to follow. As we document below, income and consumption per capita grew at healthy rates in the 1980s and economic inequality was at least not rising (and quite possibly falling), whereas in post-unification Germany per capita income and consumption grew at lower rates and became less equally distributed (depending on the economic variable considered, substantially so).

In terms of the institutional and political background, as a first approximation, the decade prior to unification in West Germany was characterized by fairly constant economic policy; no major reforms in the tax and social insurance systems occurred. Again, broadly speaking the period following the German unification is characterized by policy reforms attempting to deal with the consequences of this massive and quite unexpected political and macroeconomic shock. ${ }^{3}$ These reforms, as well as the adoption of West German institutions in East Germany (such as the West German PAYGO social security system and the unemployment insurance system), resulted in massive income transfers from the West to the East. For example, in 1991 they amounted to 113 billion DM, or 7000 DM per capita, about 1/3 of disposable income per capita in the East and more than double the total disposable income per capita in Poland at the time (see Sinn and Sinn (1992), table II.2). While these transfers were to a large extent financed by an increase in government debt, tax increases (mainly the so-called Solidaritätszuschlag, a $7.5 \%$ surcharge applied to the general income tax burden ${ }^{4}$ ) significantly

\footnotetext{
${ }^{3}$ For a comprehensive account of the economic aspects of the German unification, see Sinn and Sinn (1992).

${ }^{4}$ The surcharge applies to the personal income tax, capital income tax and corporate income tax, not to income itself. East and West German households both have to pay the
} 
contributed to the financing of these transfers, and may have had an impact on inequality between the East and the West, and within the former Western part of the country. ${ }^{5}$

\subsection{The Data ${ }^{6}$}

We will make use of two large household level data sources for Germany that contain partial information on wages, hours worked, income, consumption, and wealth: the EVS (Income and Expenditure Survey, Einkommens- und Verbrauchsstichprobe in German) and the GSOEP (German Socioeconomic Panel). ${ }^{7}$ We now describe the EVS and the GSOEP in greater detail. ${ }^{8}$

\subsubsection{The German Socio-Economic Panel (GSOEP)}

The GSOEP is an annual household panel, comparable in scope to the American PSID. ${ }^{9}$ It was first conducted in 1984 in West Germany with about in 4500 households. ${ }^{10}$ In the spring of 1990, i.e. after the fall of the Berlin Wall but before official German reunification, 2170 households from East Germany

surcharge. The rate was lowered to $5.5 \%$ in 1998 .

${ }^{5}$ In 2003 the so-called agenda 2010 was announced, a substantial reform of the German social insurance system. While most of the measures introduced under this reform did not become effective until after our data sample ends, it is conceivable that early effects of the agenda are visible in the data as early as 2004 (for the GSOEP data).

${ }^{6}$ For a general description and motivation of sample selection criteria and variable definitions we refer the reader to the data guidelines for the overall cross-country project. For a more detailed description of the German data used and our implementations of the basic guidelines with German data, see the separate appendix, available at http://www.econ.upenn.edu/ dkrueger/research/Gerapp.pdf.

${ }^{7} \mathrm{~A}$ third micro data set for Germany is the Microcensus. Since this data set only contains information on labor force participation, we will not directly use it in this study.

${ }^{8}$ Note that while both surveys are meant to be representative of the German population, differences in survey methods and variable definitions could lead to different levels and trends in inequality across the two surveys even for variables that are available in both surveys, such as various household income measures. Becker et al. (2003) provide a detailed account of the survey differences and their impact on measured income inequality levels and trends.

${ }^{9}$ We use the 95 percent random sample available to researchers outside of Germany.

${ }^{10}$ GSOEP variables in the survey year on hours and income measures refer to the previous year. So while 1984 was the first year in which the survey was conducted, 1983 is the first year for which these variables are measured. An exception is disposable household income, since household asset income was measured for the first time for the year 1984 . 
were included (this implies that East Germans are oversampled). In 1998 and again in 2000 refreshment samples increased the sample sizes substantially. The data from the GSOEP that we use is drawn from the 1984 to 2005 waves and thus extends from 1983 (1984 for selected variables) to 2004.

We use the GSOEP to construct inequality measures of wages, earnings, hours worked, and income. Since the GSOEP is a full panel, it also lends itself naturally to the estimation of the stochastic process for wages and earnings that we carry out below. On the other hand, the GSOEP contains no useful comprehensive information on consumption and wealth. ${ }^{11}$ Thus for these variables we turn to the EVS, which we describe next.

\subsubsection{The Income and Expenditure Survey (EVS)}

The EVS is a repeated cross section data set that is carried out every 5 years, starting from 1962/63. Because of data privacy reasons only the data from 1978 onwards are available for scientific research. Thus there is a total of 6 cross-sections available from the EVS for our study. The scope of the EVS is similar to the American CEX, with its main focus on detailed household consumption and wealth data. The sample size is large: about $0.2 \%$ of the population or about 60,000 households in the most recent survey. Relative to the GSOEP, only current residence is reported, making it impossible to deduce whether household members grew up in West or East Germany. The variables of interest for the current study that are available in the EVS are primarily consumption and wealth. In addition, the EVS also contains a large variety of information on earnings and income. ${ }^{12}$

\section{Trends in Wage, Income and Consumption Levels}

In this section we document how the trends in wage, income and consumption levels documented from NIPA compare to the evolution of the first moments

\footnotetext{
${ }^{11} \mathrm{~A}$ wealth questionnaire has been added to the GSOEP in 2002. In addition to the late addition of this module, the wealth data in the GSOEP are significantly bottom-coded, making this data set less than ideal for the purpose of our study with respect to the wealth variable. Therefore we document wealth inequality using the EVS.

${ }^{12}$ For only selected years, some information is also available on labor force participation and hours worked.
} 
of the corresponding income and consumption distributions from our household level data. This comparison is meant to provide a first quality check of the household level data that we use. We also display trends in labor force participation rates and average hours worked from both the micro data and aggregate statistics.

\subsection{Disposable Income}

In figure 1 we plot the evolution of annual per capita disposable income from aggregate NIPA data and from the household surveys (both EVS and GSOEP). In order to make this comparison as meaningful as possible we choose, both from NIPA as well as from the household data, as our income measure nominal disposable income of private households divided by the population $\operatorname{size}^{13}$ and the consumer price index (so that all numbers are in constant 2000 Euros). To clearly visualize the change in the sample from 1990 to 1991 due to the inclusion of East German households in the figure (as in all figures to follow) the vertical line indicates the exact point of sample change. Furthermore note that the disposable income observations in the GSOEP start only in 1984 while the EVS observations start in 1978. Thus to insure maximum comparability we start the plot in 1983 (with the second EVS observation).

The trends in income levels from the household surveys line up well with the facts from NIPA. ${ }^{14}$ There was healthy income growth in West Germany through the 1980's (at roughly 2.5\% per year from 1983 to 1990, and consistent between NIPA and GSOEP), followed by a drop through the composition effect at the time of reunification ${ }^{15}$. Both the healthy growth in per capita income as well as the decline between 1990 and 1991 is of very similar

\footnotetext{
${ }^{13}$ In the case of GSOEP and EVS, this is measured as the number of individuals (not households), in the sample. In contrast to the inequality statistics where we impose more stringent sample selection criteria, all households for which information is available for the variable under consideration are included in the calculation of the means from the household-level data.

${ }^{14}$ The levels are lower in GSOEP, which can at least partly be explained by the fact that the very rich are not represented well in GSOEP.

${ }^{15}$ In both household data sets as well as in the NIPA data East German households first enter in 1991. Since the EVS records data only every five years (that is, 1988 is the last year with the exclusively West German sample, and 1993 is the first year with the unified German sample), the per capita income drop due to German reunification is not visible in this data set.
} 


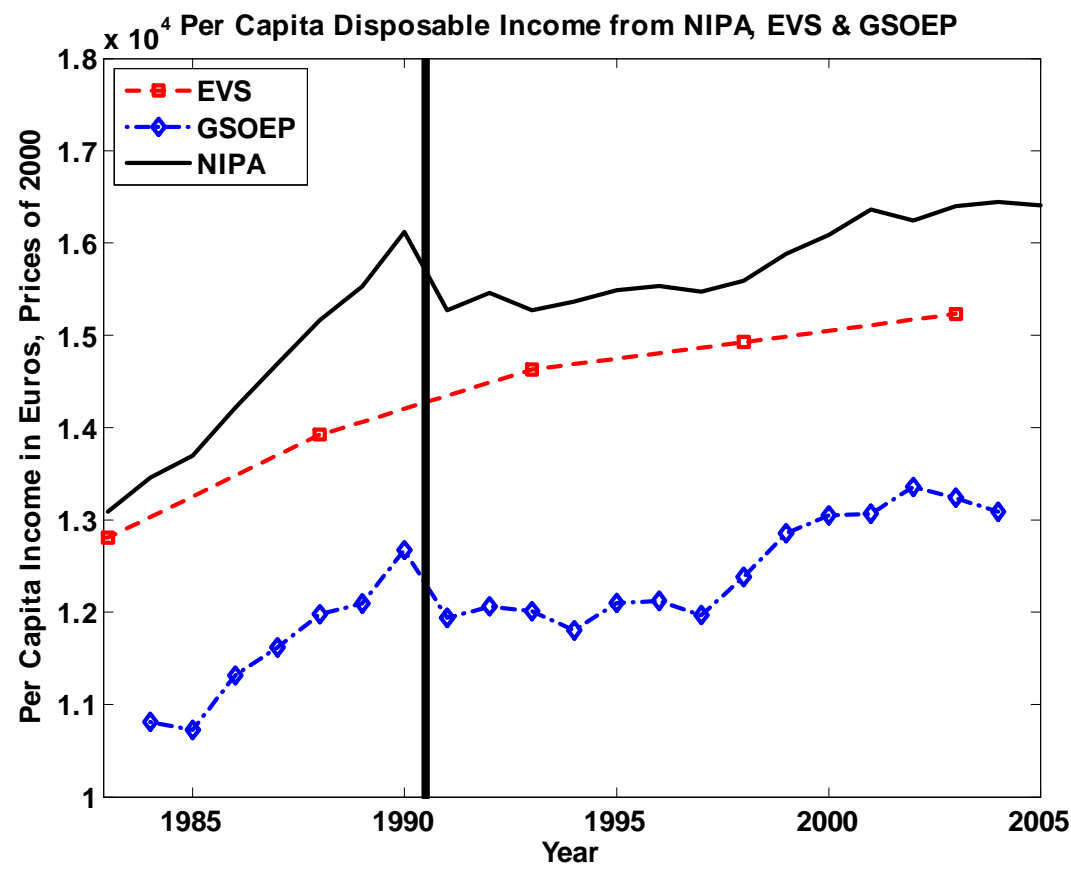

Figure 1: Per Capita Disposable Income, NIPA, GSOEP and EVS

magnitude in the aggregate data and the household data from the GSOEP.

Following the unification the compounded growth rate of real per capita disposable income from 1991 to 2004 is $9.6 \%$ in the GSOEP household data set $(0.7 \%$ per annum) and $7.7 \%$ (0.6\% per annum) in the NIPA data, while the EVS records a growth rate of 4.1\% (0.4\% per annum) between 1993 and 2003. Therefore all data sets display slow growth in income per capita in post-unification Germany (with only the period between 1996 and 2000 displaying significant growth at all). Overall, the trends in real disposable income levels per capita are remarkably similar for the GSOEP on which we will base our inequality trends analysis for wages, hours worked, earnings, and income and the NIPA, and at least plausibly similar for the EVS and NIPA (we do not use EVS data for our income inequality analysis). ${ }^{16}$

\footnotetext{
${ }^{16}$ Becker et al. (2003) also document that mean income levels are higher in the EVS than in the GSOEP and attribute the differences (which are of roughly similar magnitude than the ones documented here) to the methodological differences between the two surveys (mainly the book-keeping approach used in the EVS versus retrospective questions in the
} 


\subsection{Wages}

Figure 2 displays average real wages from aggregate labor statistics and from the GSOEP. The aggregate statistics measure gross wages and salaries per hour worked, and therefore do not subtract taxes and other social insurance contributions. ${ }^{17}$ The average wage measure from the GSOEP micro data is also a gross wage, and is derived by dividing annual wages or salaries by annual hours worked. This implies that if annual hours are measured with error, so will be hourly wages from the GSOEP. ${ }^{18}$ Both the aggregate and the micro wage data are deflated by the German CPI and expressed in constant 2000 Euros.

The figure displays several interesting facts. As for disposable income, average wages from NIPA show a healthy growth of $2.3 \%$ per year from 1983 to 1990, a drop in 1991 (because East German wages were initially substantially lower than West German wages), and slower wage growth after 1991. The average growth rate of real wages as measured by aggregate statistics between 1991 and 2004 is a meager 0.9\%, again consistent with the growth rate of disposable income in aggregate data documented above. The micro data paint a similar picture in the post-unification period, with average wage growth rates of $0.8 \%$ per year $(0.6 \%$ for males and $1.2 \%$ for females). On the other hand, the micro data do not display the very strong growth in real wages in the pre-unification period that the aggregate data show. While wages for the entire sample do grow by about $1.2 \%$ p.a. in the years prior to unification ( $1.1 \%$ for males and $1.6 \%$ for females) the micro data does not fully match the strong growth of wages $(2.3 \%$ at an annual level) observed at the aggregate level for wages. As we will discuss further below, this divergence is likely due to differences in the aggregate and micro trends in hours worked (in conjunction with the way wages are derived from the GSOEP, by dividing annual earnings by measured hours worked).

GSOEP, as well as the fact that taxes paid are imputed, and thus likely overstated, in the GSOEP and directly surveyed in the EVS).

${ }^{17}$ Source for NIPA wages: Institut für Arbeitsmarkt- und Berufsforschung (IAB).

${ }^{18}$ The GSOEP tends to overstate hours worked, especially because it does not account well for vacation days and sick leave. This leads to an underestimation of wages. If the overstatement of hours has become more severe over time for some reason, then growth of average wages in GSOEP will be biased downwards. While average vacation days have increased over our sample period, sick leave days have rather decreased. 


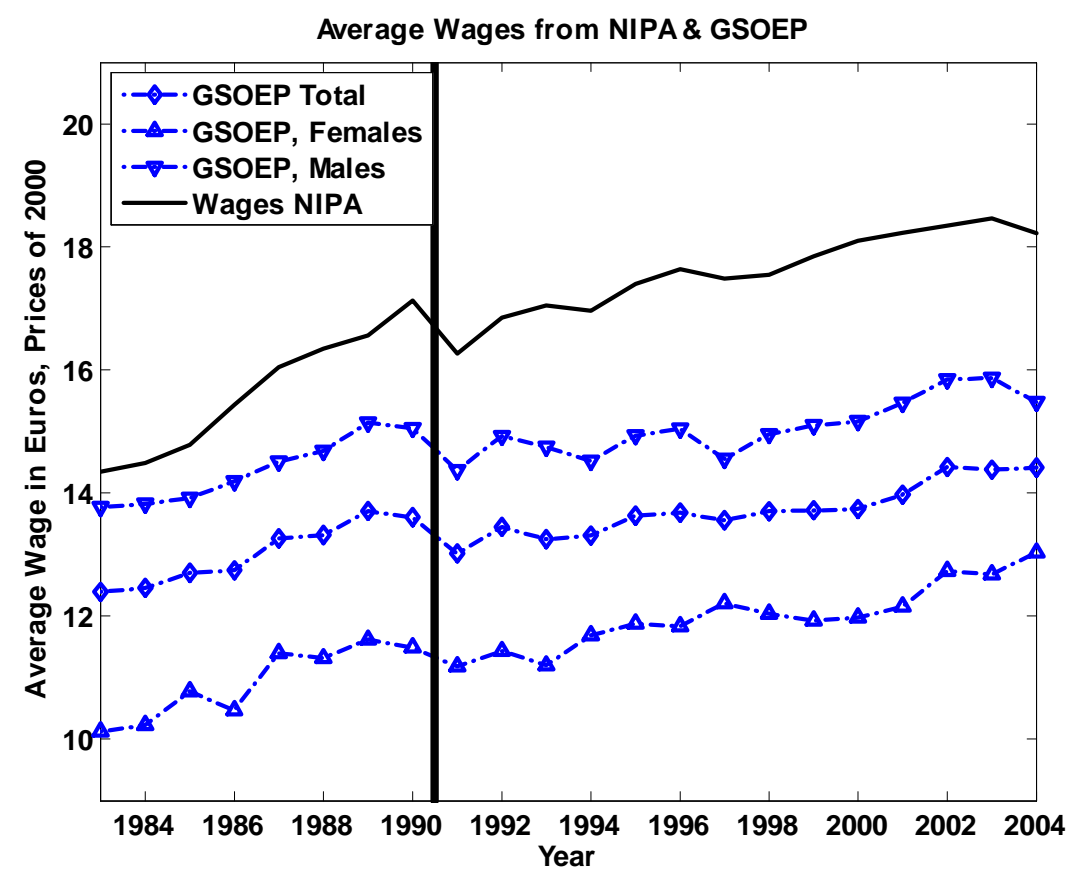

Figure 2: Average Wages, NIPA and GSOEP

\subsection{Consumption}

We now turn to consumption. In figure 3 we plot per capita real consumption against time for two measures of consumption: nondurable consumption and nondurable consumption plus (imputed) rent payments by households. ${ }^{19}$ For German micro data, the only available data source is the EVS, which is conducted only every five years; therefore the plots for micro data contain only six observations, and higher frequency fluctuations in real per capita

\footnotetext{
${ }^{19}$ For the NIPA data we summed up nominal consumption expenditures for food and tobacco, transportation, entertainment, outside dining and hotel services and miscellaneous expenditures and deflated nominal expenditure by the CPI, in order to be as comparable as possible to the EVS micro data. The resulting variable is used as nondurable consumption. We add expenditures for housing, water, gas and electricity to obtain the nondurables-plus consumption measure.

The EVS nondurable consumption measure includes food, clothes, energy, health, bodycare, travel, communication, education, and household services. We add (imputed) rent to obtain the nondurable-plus consumption measure.
} 
consumption cannot be compared to NIPA data.

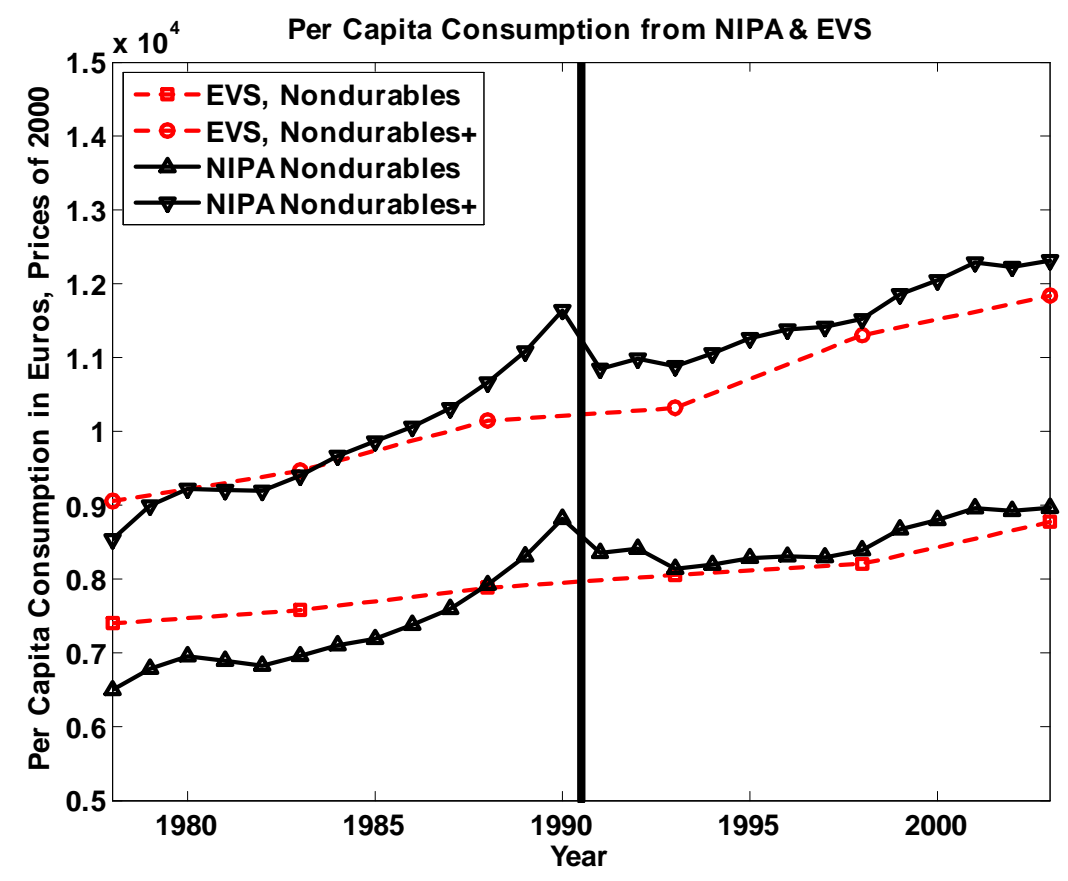

Figure 3: Consumption per Capita, NIPA and EVS

First, both aggregate and household data display similar trends after reunification and line up well even in levels. In fact, from 1993 to 2003, per capita real nondurable consumption growth averaged about $1 \%$ annually in both the NIPA and the EVS. Nondurables plus (imputed) rents increased at a somewhat fast rate of $1.25 \%$, again fairly uniformly across the two data sets. Also the EVS data for 1988 line up well with NIPA. The main deviation between micro and macro consumption data occurs between 1978 and 1988 where NIPA nondurables grow at an annualized rate of $2 \%$ (2.2\% for nondurables+) and the EVS micro data display an annualized growth rate of $0.6 \%$ for nondurables and $1.1 \%$ for nondurables+. Interestingly EVS not only understates consumption growth, but also income growth over this time period, relative to NIPA (see figure 1). Thus, while it is certainly conceivable that the small differences in the definition of the consumption aggregates between NIPA and EVS are partially to blame for this divergence, the facts 
that the latter sample period does not display the same problem, that the divergence also occurs for income and that the components that make up nondurable consumption are rather well aligned between NIPA and EVS lead us to conclude that other reasons must mainly be responsible for the difference in consumption growth over the 1978 to 1988 period. ${ }^{20}$ While this difference is not as massive as e.g. the divergence displayed in a comparison between U.S. CEX household and aggregate consumption data, it is a point of concern that we have not seen documented elsewhere and that deserves further empirical investigation.

\subsection{Participation Rates and Average Hours Worked}

In order to get a sense whether the GSOEP data capture basic trends in labor market activity of individuals we now contrast participation rates and average hours worked from aggregate statistics and from the GSOEP. In figure 4 we plot the aggregate employment rate (defined as the ratio between employed individuals aged 16-65 and the entire population aged 16-65). ${ }^{21}$ In addition we display full-time and part-time participation rates from the GSOEP, where people self-report whether they have participated in the labor market, and if so, whether they have participated full-time or part-time. ${ }^{22}$

Both from the Mikrozensus as well as from the GSOEP we observe an increase in the employment rate prior to unification, and a subsequent decline. The GSOEP breakdown also shows a substantial increase in part-time participation throughout the sample period, in absolute numbers and even more dramatically, relative to full-time participation. Note that part-time participation is particularly high for women in Germany: about two-thirds of all working women work part-time.

\footnotetext{
${ }^{20}$ We experimented with other household weights and sample selection criteria, without major changes in the growth rate of per capita consumption between 1978 and 1988 in the EVS.

${ }^{21}$ According to this definition, unemployed individuals do contribute to the denominator, but not the numerator, of this statistic. The source of the aggregate statistics is the German Mikrozensus, that is, this statistic is based on household data as well (but a source that is independent of the GSOEP, although the GSOEP uses the Mikrozensus to obtain sample weights for its households).

${ }^{22}$ For the participation variable, East German households enter the GSOEP sample in 1990, and the Mikrozensus in 1991. We therefore include two vertical lines into the plot.
} 


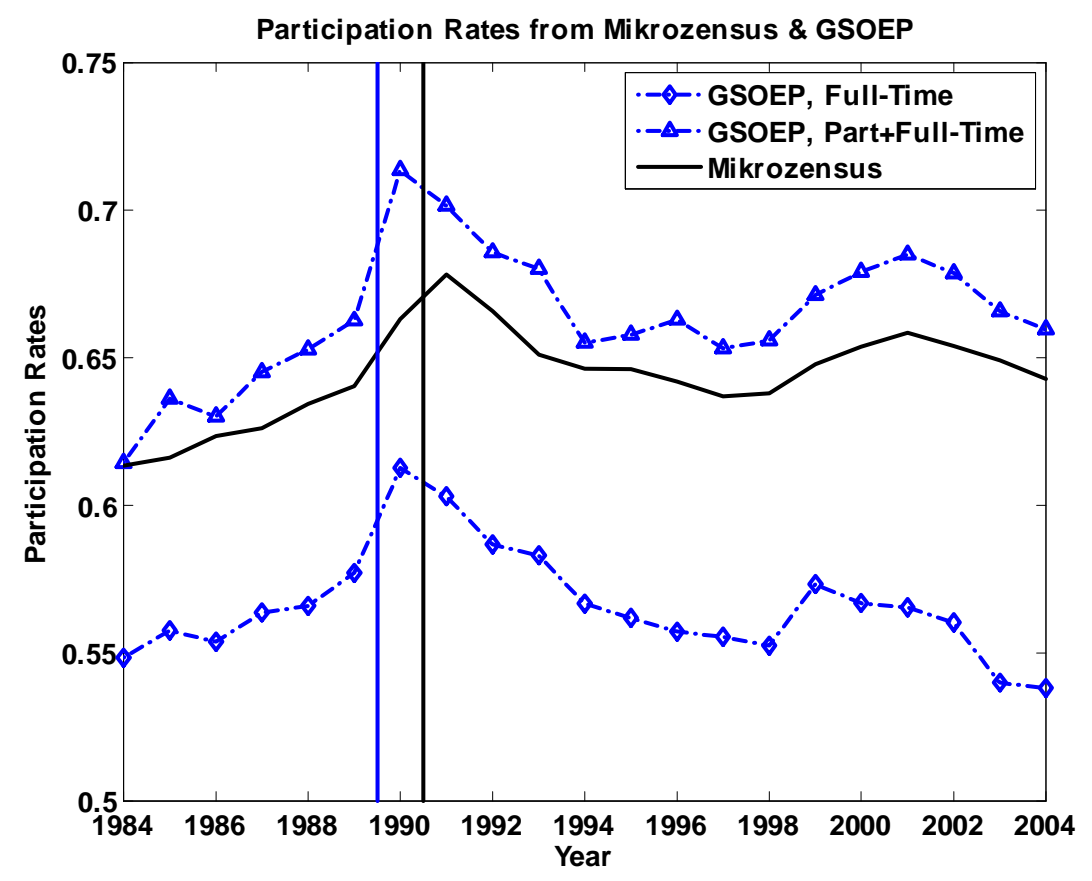

Figure 4: Participation Rates, Mikrozensus and GSOEP

Trends in aggregate labor supply are not only caused by changes in participation rates over time, but also by changes in average hours worked. In figure 5 we therefore document average levels of hours of employed (including self-employed) individuals, for males, females and the entire sample in the GSOEP. The corresponding data from NIPA also measure average hours worked by employed and self-employed combined ("Erwerbstätige"). All measures of hours therefore exclude individuals that are not employed, i.e. work zero hours.

For annual hours worked the aggregate statistics show a substantial decline, roughly by 260 hours, from 1700 hours in 1983 to 1440 hours in 2004. The decline in hours is fairly uniform across the pre- and post-unification period.

Comparing hours level and trends to micro data from GSOEP, we first observe that GSOEP hours are substantially higher. A large part of the reason for this difference is that the household data account for days not worked due to vacation or sick days only in a very limited way. This upward 


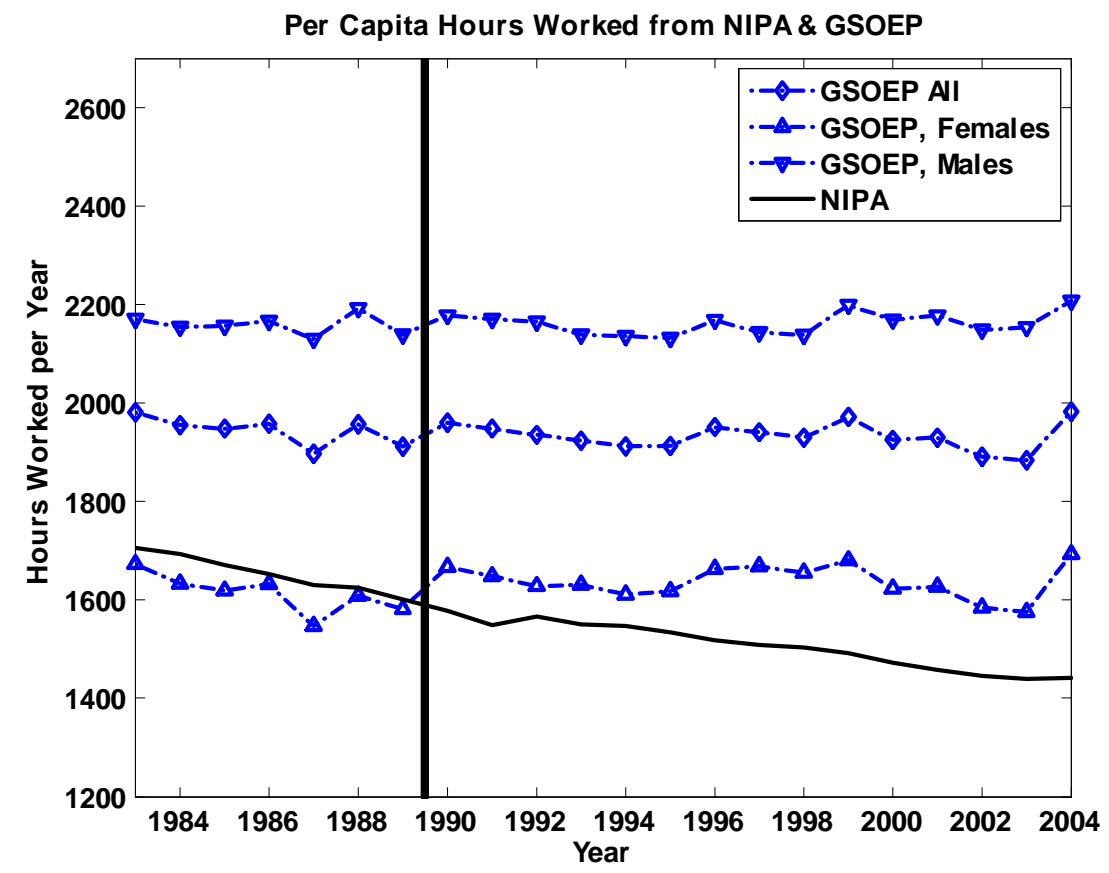

Figure 5: Average Hours Worked, NIPA and GSOEP

bias in average hours is clearly visible in the figure. Second, GSOEP data do not display a significant decline in average hours over time, neither for males nor females. ${ }^{23}$ To the extent that over the last 25 years vacation days have increased, not only are GSOEP mean hours likely overstated, but increasingly overstated..$^{24}$ In our view, this might partially explain the lack of decline in average hours worked observed in GSOEP data. However, the large magnitude of the divergence makes it likely that other determinants of this divergence between micro and macro data are important as well. This is an issue that requires further investigation in future work.

\footnotetext{
${ }^{23}$ For females, the upward jump in average hours worked between 1990 and 1991 is due to fact that East German females that enter the sample in 1991 work significantly longer hours on average than their West German counterparts.

${ }^{24}$ The average number of vacation days has increased from about 26 in 1980 to 29.5 in 1994 and has remained farily constant since then (see Bundesministerium für Verkehr, Bau und Städteentwicklung (2007), figure 27). On the other hand, average sick days have decreased over time.
} 


\section{Inequality Trends over Time}

After having confirmed that our household data sets display the same basic stylized facts for the levels of per capita income, consumption, and participation rates (and less so for hours and consequently wages), we now turn to the main object of interest, the evolution of economic inequality over the last two decades in Germany. We start with individual wages and hours worked, and then move to earnings, income, consumption, and wealth. ${ }^{25}$

\subsection{Wage Inequality}

Figure 6 displays the evolution over time of four measures of the cross sectional dispersion in wages. The sample based upon which these statistics are computed include both males and females, and individuals with all levels of education. From 1991 on the sample includes East German households as well. ${ }^{26}$ It does exclude the top $0.5 \%$ of wages for each year, because potential measurement error in hours worked leads to extremely high wage observations for a small set of households (remember that wages are derived by dividing reported annual earnings by reported annual hours). The inclusion of these observations makes especially the pre-unification inequality measures very noisy. ${ }^{27}$ The inequality measures we use (and will continue to use in most of this paper) are the variance of the log, the 90-50 and 50-10 percentile ratios

\footnotetext{
${ }^{25}$ We investigated the precision of our point estimates for the inequality statistics of selected variables (mainly income and consumption) with the bootstrap. The confidence intervals around the point estimates both from the GSOEP as well as the EVS are small, rarely exceeding a total size for the $95 \%$ confidence interval of 6 points for the variance of the log. We therefore suppress confidence intervals in the figures in the paper.

${ }^{26}$ We devote special attention to the distinction between East and West Germany after the reunfication in section 7 . The main problem in merging data for both regions is the potential for differences in prices across regions, possibly leading to an understatement of all real variables in East Germany because of a lower price level there. In the main analysis we adopt the recommendation of the overall data project and use a common price deflator for all household types, but a separate one for East and West Germany until 1999.

${ }^{27}$ The censoring at the top that we employ is not innocuous however, since, as Dustmann et al. (2007) document, strong wage growth at the very top of the wage distribution is an important component of the overall picture of German wage inequality trends. When comparing our results to theirs, this has to be kept in mind. Note, however, that the percentile ratios are not significantly (and in the case of the 50-10 ratio, not at all) affected by our censoring choice.
} 
and the Gini coefficient. ${ }^{28}$

From figure 6 we obtain three main facts, fairly robustly across the different inequality measures. First, wage dispersion has not noticeably increased during the 1980s. The only statistic that shows a significant increase is the 50-10 ratio, which suggests that to the extent that wage inequality increased during that period, it did so at the lower end of the distribution.
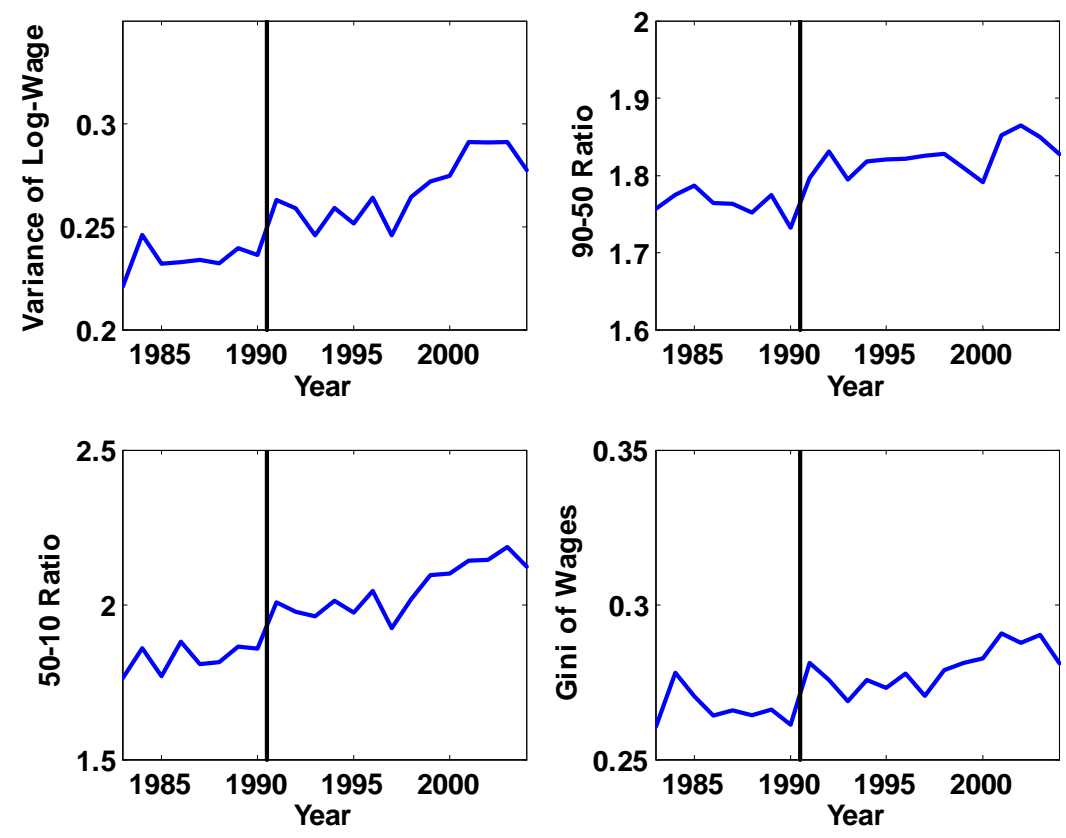

Figure 6: Wage Inequality Trends, 1983-2004

Second, wage inequality rises noticeably between 1990 and 1991 when the East German sample enters the GSOEP. Third, wage inequality rises in the 1990s, especially after 1997 (while it is roughly flat after the reunification jump in 1991 until 1997, and declining for some inequality measures). This phenomenon is present in all parts of the wage distribution, as all statistics

\footnotetext{
${ }^{28}$ Different inequality statistics for the same variable are always computed from the same sample; therefore observations with nonpositive values are always discarded (because the variance of logs does not permit these values). Unless otherwise noted, no further sample selection criteria are applied, over and above the sample selection criteria imposed by the overall data project. In the appendix we discuss the details how the general guidelines for sample selection were implemented in our German data.
} 
show a similar trend, but appears most starkly at the lower tail of the distribution. The 50-10 ratio increases from 1.86 to 2.12 between 1997 and 2004, whereas the 90-50 ratio only increases by 10 points, from 1.73 to 1.83 . Compared to the increase in wage inequality in the US, for example, German wage inequality started to rise about two decades later, and the increase has so far been modest, even if one includes the composition effect stemming from the inclusion of the East German sample in 1991 (in Germany the variance of log-wages increased by 4 percentage points between 1990 and 2004, relative to an increase in excess of 10 percentage points in the US between 1975 and 1990).

We now decompose the trends in wage inequality further, in order to obtain a better sense what trends underlie the patterns of roughly unchanged inequality in West Germany prior to unification and the somewhat more pronounced increase since then. In figure 7 we plot the trends in the experience wage premium, the education wage premium, the gender wage premium, and the trend in residual wage dispersion. The education wage premium is computed as the average wage of a university graduate, divided by the average wage of an individual without a university degree. Note that the share of individuals with a university degree in our wage sample is about $20 \%$, significantly lower than in other European countries and the US. ${ }^{29}$ The experience wage premium is calculated as the average wage of individuals of ages 45-55, relative to the average wage of individuals aged 25-35, whereas the gender wage premium is the ratio of the average hourly wage of a male individual divided by the average wage of a female individual. Finally, residual wage dispersion is measured as the log variance of the residual of a wage regression on dummies for the individual's education and gender, a quartic in age, and an East/West dummy that refers to the residence before reunification. While there are noteworthy trends in the different wage premia (average wages of females significantly catching up with those of males throughout the sample, a small secular increase in the experience premium and a somewhat declining education premium) residual wage dispersion displays essentially the same stylized facts as "raw" wage dispersion: it is roughly constant during the 1980s, followed by an increase in the post-unification years, particularly (but not exclusively) after 1997.

A unique feature of Germany is the inclusion of a sample of households

\footnotetext{
${ }^{29}$ Note, however, that certain (especially technical) degrees that typically would be earned in college in the US are obtained through vocational training in Germany.
} 

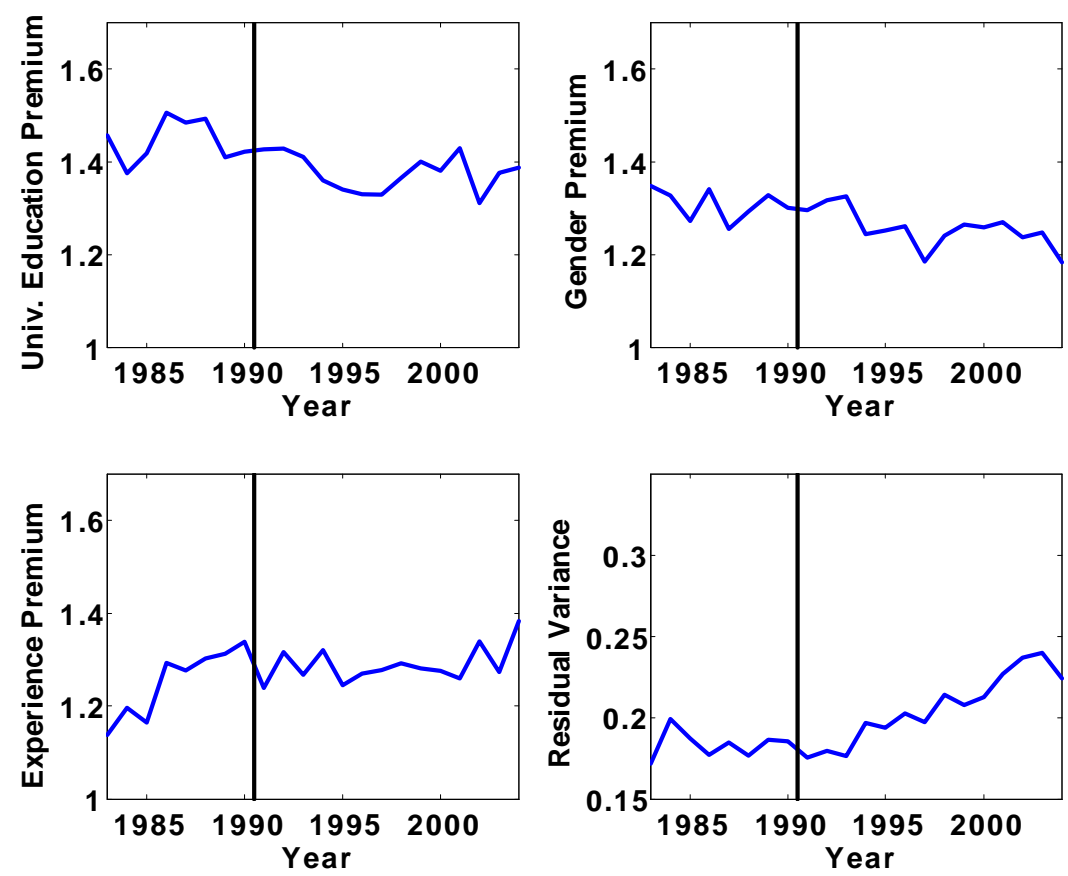

Figure 7: Decomposition of the Trends in Wage Dispersion

from the East in 1991. The West-East wage premium was substantial at 1.75 in 1991 and has since declined to about 1.4 in 2004. Thus while gross wages are still significantly higher in the West than in the East, this contributor to overall wage inequality has lost in importance in the last decade. We will return to the question how inequality in wages, income and consumption was affected by the inclusion of the East German sample in section 7 by decomposing overall inequality into inequality trends within East and West Germany, and inequality trends between the two regions.

\subsection{Inequality in Hours Worked}

To obtain a coherent picture about how inequality in economic welfare has developed over time it is crucial to document trends in the dispersion of hours worked. First, time spent not working either generates utility directly through leisure or indirectly through consumption services from home production. Second, hours worked in conjunction with wages determine earnings, 
which are a key determinant of consumption, the second main driving force of economic welfare.
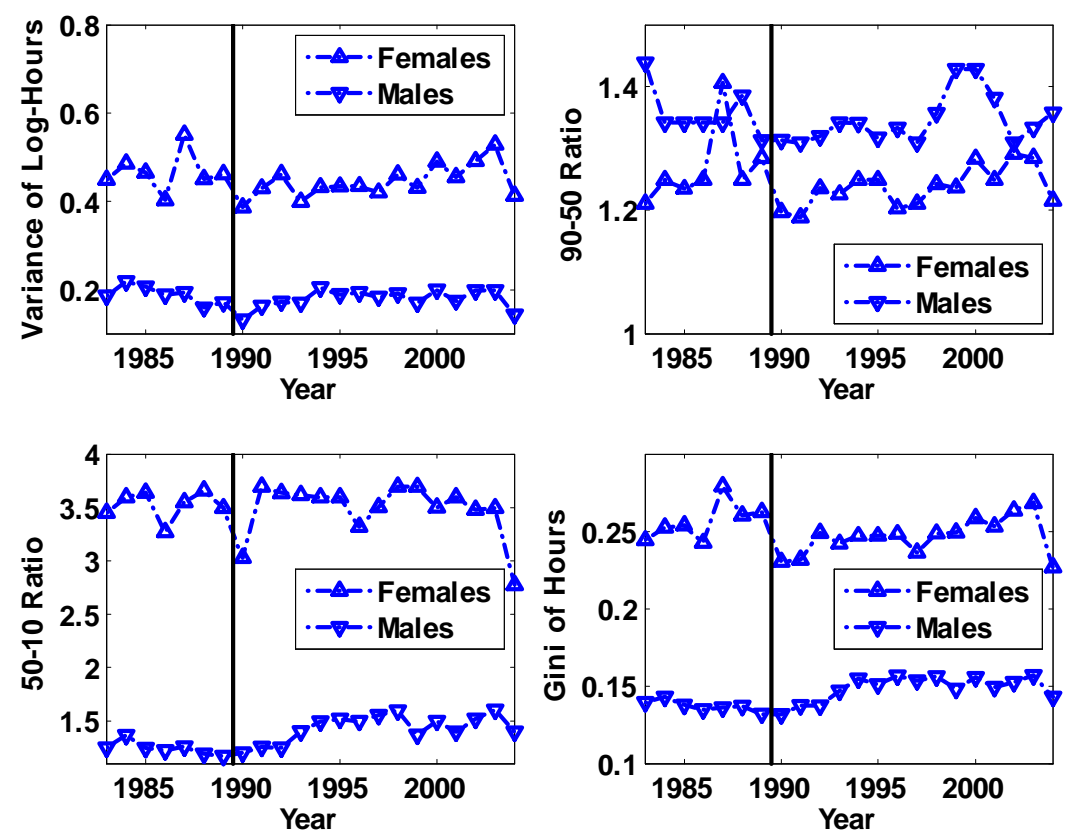

Figure 8: Trends in the Dispersion of Hours Worked, by Gender

In figure 8 we display the same inequality statistics previously employed for wages, but now for hours worked. Since average hours worked and participation rates vary significantly between males and females, we plot the hours-inequality trends separately for both genders. Several observations are worth mentioning. First, the dispersion of hours worked is substantially larger among females than males. ${ }^{30}$ This is mainly due to the much larger extent of part-time work among females in Germany (of those women that work, about two-thirds work part-time) ${ }^{31}$ In terms of inequality trends, the

\footnotetext{
${ }^{30}$ The one exception is the 90-50 ratio, which is higher for males due to the more substantial fraction of males working in jobs with hours that substantially exceed the typical work week of (at most) 40 hours. The 50th percentile of hours worked is about 300 hours per year higher for males than for females, whereas the 90th percentile displays men working 500 hours more than females.

${ }^{31}$ Since we exclude individuals working zero hours when calculating all hours inequality statistics, the much larger share of females not working does not affect the level of hours
} 
(modest) decline in hours inequality among males prior to unification is visible for all four statistics; the same appears to be true for females, although the data is a bit more noisy. Second, post-unification Germany is characterized by a slight increase of hours inequality for both males and females, although the magnitudes are smaller than those for wages.

Taking the evidence for wages and hours together we would expect the trends in wage and hours dispersion to translate into a corresponding (weak) fall in earnings dispersion prior to the reunification, and a more pronounced rise afterwards. Note however, that changes over time in the correlation between individual wages and hours may lead to trends in earnings (and thus in income and consumption) inequality that deviate from the previously documented trends. ${ }^{32}$ In practice, this point is of minor quantitative importance. The correlation between wages and hours is very stable over time and slightly negative at -0.03 for females. For males there is a modest upward trend in the correlation, from about -0.2 in the mid-80s to approximately zero in $2004 .^{33}$

In addition, we measure wages and hours on an individual basis, whereas with earnings and income we will switch our unit of analysis to the household level. Therefore changes in the correlation of spousal hours and wages may further complicate the relationship between individual wage and hours inequality on the one hand and household earnings inequality on the other hand.

\subsection{Earnings Inequality and its Decomposition}

As discussed above, the trends in wage and hours inequality suggest that labor earnings inequality should have been roughly constant in the years prior to unification and more markedly increased in post-unification Germany. In

inequality, by construction.

${ }^{32}$ This is most direct for a one-earner household since then labor earnings $y$ is the product of the hourly wage $w$ times hours worked $h$. Thus

$$
\operatorname{Var}(\log y)=\operatorname{Var}(\log h)+\operatorname{Var}(\log w)+2 \operatorname{Cov}(\log h, \log w) .
$$

\footnotetext{
${ }^{33}$ The correlation between wages and hours is somewhat noisy and may be affected by ratio bias if hours are measured with error, since wages are measured as annual earnings divided by hours. Thus we focus on the trend of the correlation (which should be unaffected by the bias as long as measurement error is constant over time) rather than the slightly negative levels.
} 
order to assess this conjecture we now plot the trends in earnings inequality. Moving from hours and wages to earnings we face the problem that the former variables are measured on an individual basis whereas earnings and income are measured on the level of the household. We therefore first investigate basic earnings inequality trends, and then display how these trends are potentially shaped by changes in household size and composition, as well as by changes in the composition of the sample along various dimensions. We finally document the evolution of earnings inequality in more detail for our preferred measure of household labor earnings.

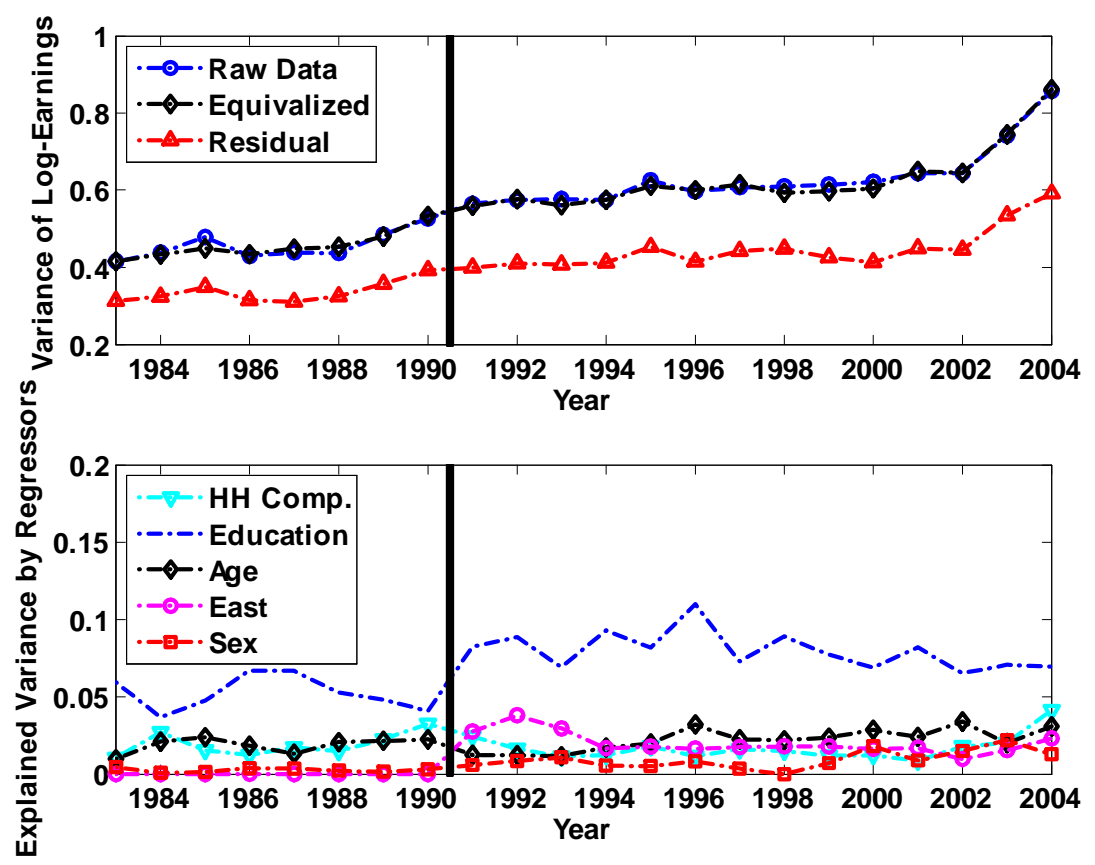

Figure 9: Decomposition of Earnings Inequality

The first panel of figure 9 contains the time trends of household earnings inequality, as measured by the variance of log-household earnings, for three measures of household earnings. These measures are distinguished by the extent to which we control for observable differences of households. We plot inequality in unadjusted household labor earnings and in household earnings adjusted by family size. This adjustment is accomplished (here and for all other variables discussed below) by dividing the raw observations by the 
OECD equivalence scale. ${ }^{34}$ Finally we display inequality in residual household earnings, where the residual is constructed by regressing equivalized household earnings on dummies for household composition, education, sex of the household head, a quartic in age and an East/West dummy (for the data starting from 1991).

We first observe that using earnings data that are deflated by family size makes almost no difference for inequality levels or trends, relative to the raw data. ${ }^{35}$ Controlling for observable differences across households through the regression not surprisingly reduces earnings inequality. Observables can account for about $25-30 \%$ of the cross-sectional variance in household earnings, and this fraction is fairly constant, but slightly increasing, over time. In the second panel we decompose in more detail which observable differences across households are mainly responsible for explaining household earnings differences.

Before turning to this analysis we want to highlight that, independent of the earnings measure used, the data show no strong trend in earnings inequality prior to the German unification (but a small increase in the years just prior to unification), and an upward trend afterwards that is almost exclusively driven by an increase in earnings inequality after the year 2000 . Overall, the variance in log-household earnings increased by 0.44 in the period between 1983 and 2004, with about half of this increase attributed to the years 2000 through 2004. The relative magnitudes for equivalized household earnings and the earnings residual are similar. Thus the upward trend in hours and wage inequality in post-unification Germany (especially in the most recent years of our sample) translates into a corresponding substantial increase in household earnings inequality over the last 15 years. On the other hand, the slight increase in wage dispersion (and the very slight decline

\footnotetext{
${ }^{34}$ More precisely, this equivalence scale (sometimes also called the "Oxford" scale), assigns a value of 1.0 to the first household member, a value of 0.7 to each additional adult and a value of 0.5 to each child (i.e. members 16 and younger).

${ }^{35}$ Note that

$$
\operatorname{Var}\left(\log \left(y_{i t} / s_{i t}\right)\right)-\operatorname{Var}\left(\log \left(y_{i t}\right)\right)=\operatorname{Var}\left(\log \left(s_{i t}\right)\right)-2 \operatorname{Cov}\left(\log \left(y_{i t}\right), \log \left(s_{i t}\right)\right)
$$

Earnings and the equivalence scale are weekly positively correlated in the GSOEP, roughly offsetting the cross-sectional variance in the equivalence scale. Below we will find that the equivalence scale is more strongly positively correlated with consumption, and thus for this variable equivalization will make much more of a difference for inequality levels (but not so much for their trends, as we will show below).
} 
in hours dispersion) prior to unification manifest themselves in a similarly modest increase in household earnings inequality (about a 11 points increase in the variance of log-earnings between 1983 and 1990).

The main finding of our decomposition analysis is that the majority of earnings inequality is attributable to residual earnings inequality that cannot be explained by differences in observable household characteristics. Among the observable characteristics, the education level of the household accounts for most of the explained cross-sectional variance (close to $50 \%$ on average over the sample years), see the bottom panel of figure 9 . Here education is measured by a complete set of dummies for the highest education level of the household head and spouse, with the education level being measured as either completed college, completed vocational training, completed high school or no high school completion. The other observable characteristics (household age, composition, gender of the head) account for a non-negligible, but rather modest $10 \%$ share of the overall cross-sectional variance in log-earnings. The East-West dummy is most important directly after the East sample enters, but then its importance diminishes over time. We will confirm the declining importance of East-West differences for overall German inequality in our analysis in section 7 below.

We now plot the time trend of equivalized (by the OECD equivalence scale) household log-earnings inequality for various inequality measures in figure 10. The substantial increase in earnings inequality after the unification is clearly visible for all measures employed. In contrast, the picture prior to unification is more dispersed. In the 1980s the $90-50$ ratio, the $50-10$ ratio and the Gini suggest rather constant earnings inequality, whereas the variance of log-earnings (as documented above) displays a modest increase.

\subsection{From Wage to Income Inequality}

Before turning to consumption and wealth inequality we want to document to what extent inequality trends in individual labor market opportunities and decisions (that is, wages and hours) translate into inequality trends in household consumption and savings opportunities, as proxied by various measures of income.

In figure 11 we therefore display the variance of various log-income measures (wages, earnings, adding private and then public transfers and taxes), starting from wages of the head of the household, and ending at household disposable income. We compute all inequality statistics for the nonequival- 

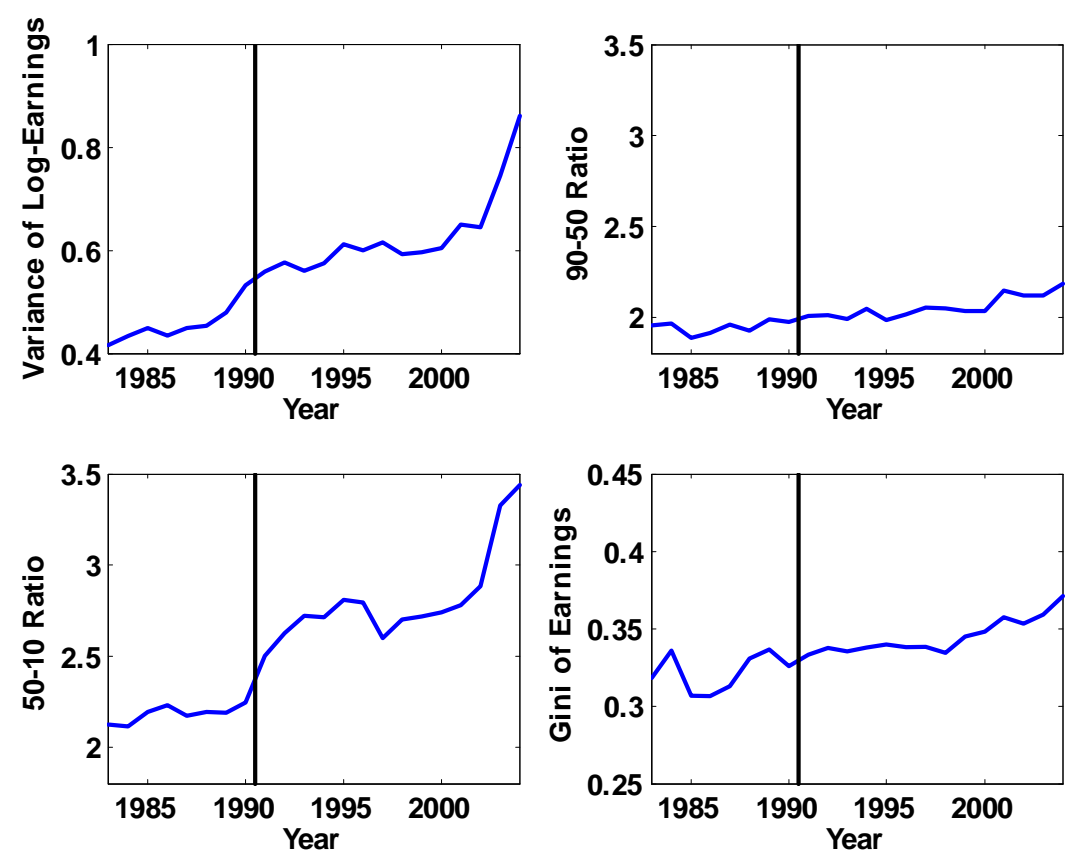

Figure 10: Trends in Earnings Inequality

ized (by household size) data. As the previous analysis documented, whether one uses equivalization or not does not affect the results for earning and income in a significant way. Similarly, in figure 12 we display the corresponding figure with inequality measured by the Gini coefficient.

As documented above for the entire sample (not only household heads as displayed here), the cross-sectional variance of wages of household heads is roughly stable prior to unification and has increased since then. In fact, conditioning on household heads only, wage inequality in the 1980s in West Germany is even flatter (showing a slight decline by 1.5 points between 1984 and 1990) than for the entire wage sample. Inequality in earnings (of household heads as well as overall household earnings) show a more pronounced increase in inequality after unification, while there is no noticeable increase in inequality prior to 1991 for earnings of heads, but more of an increase in total household earnings. In terms of levels, head earnings are more unequally distributed than head wages. This in turn is due to the fact that household head log-hours have a substantially positive variance. The covariance be- 


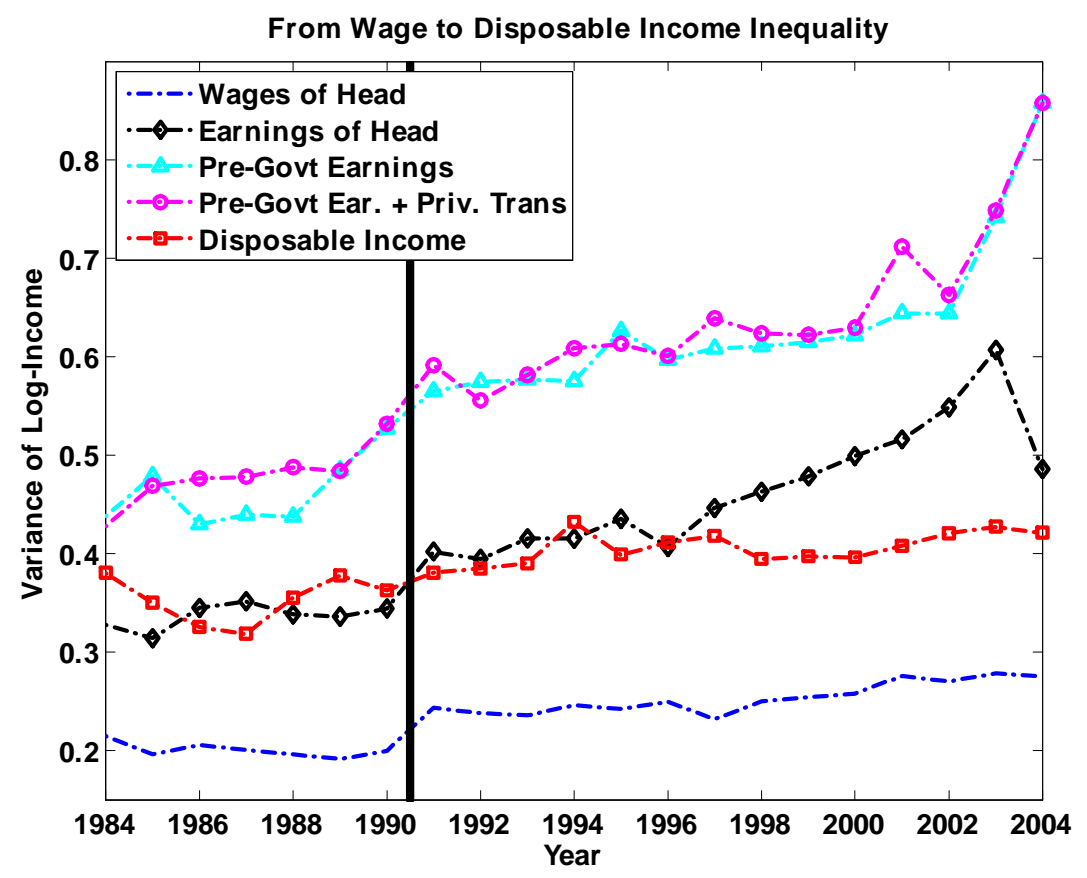

Figure 11: From Wage Inequality to Disposable Income Inequality

tween wages and hours of household heads, on the other hand, is negative ${ }^{36}$ (but increasing over time).

Similarly, household earnings show a larger cross-sectional dispersion than earnings of household heads, indicating a positive correlation between earnings of heads and other members of the household. Adding private transfers to household earnings makes no difference for cross-sectional inequality trends as these transfers are quite small for just about all households. Finally, and possibly most importantly, we observe that the government tax and transfer system reduces the level of income inequality, relative to pre-government earnings concepts, and substantially affects its trend as well. ${ }^{37}$ For the entire sample the variance of disposable household income is only about $69 \%$ of

\footnotetext{
${ }^{36}$ As described before, this might be due to a ratio bias, since wages are computed as earnings divided by hours.

${ }^{37}$ By moving from earnings to disposable income we also add asset income to earnings. Asset income, although substantially unequally distributed, is small for most households in the GSOEP and thus does not strongly affect the measured inequality trends for income.
} 
that of pre-tax household earnings, and that ratio fell from about $80 \%$ to close to $50 \%$ at the end of our sample.

Investigating the time path of disposable income inequality we observe that it slightly fell prior to unification (by about 2 points, from 0.38 to 0.36 ) and then only slightly rose in the next 15 years after that, from 0.38 in 1991 (the first year the East sample is in our data set) to 0.42 in 2004 . As a point of comparison the variance of pre-tax household earnings rose by 29 points, from 0.57 to 0.86, in the post-unification period from 1991 to 2004.

To summarize our discussion of a wide range of earnings and income measures: in the second half of the 1980s wage, earnings and income inequality did not rise substantially, if at all. This trend changed after the German unification, with all measures of pre-tax earnings and incomes displaying a substantial upward trend. This rise in inequality in market incomes did not, however, fully translate into an equally significant increase in disposable household income inequality, leading us to conclude that the government tax-transfer system worked rather effectively, up until 2004, in providing income insurance/redistribution. ${ }^{3839}$ Figure 12 documents that, at least qualitatively, the stylized facts just described are robust to using the Gini coefficient rather than the variance of logs as our summary inequality measure. We notice though that the Gini displays a somewhat more pronounced increase in disposable income inequality in post-unification Germany than the variance of logs, especially after 1998. However, this increase in the Gini is still significantly smaller than that of household earnings, consistent with what the variance of logs displayed.

Given the apparent importance of the public tax and transfer system in mitigating the increasing trend in earnings and income inequality, we decompose the importance of taxes and public transfers for keeping income inequality from rising faster. In figure 13 we display, in deviation from the 1984 values (in order to more clearly visualize relative magnitudes of

\footnotetext{
${ }^{38}$ This is a purely positive statement and is not meant to deny the potentially detrimental effects this system had on household income levels and growth rates. It is quite possible that the massive slowdown in per capita income growth may be in part caused by exactly the policies that seem to have kept disposable income inequality rather constant despite a strong upward trend in pre-tax household earnings inequality.

${ }^{39}$ For an analysis of equivalized disposable income inequality in post unification Germany that focuses on particular income percentiles and the Gini coefficient, see Grabka and Frick (2008). They document qualitatively similar trends, but find a somewhat larger increase in disposable earnings inequality starting roughly from the year 2000 on (as we do for all pre-government income inequality measures).
} 


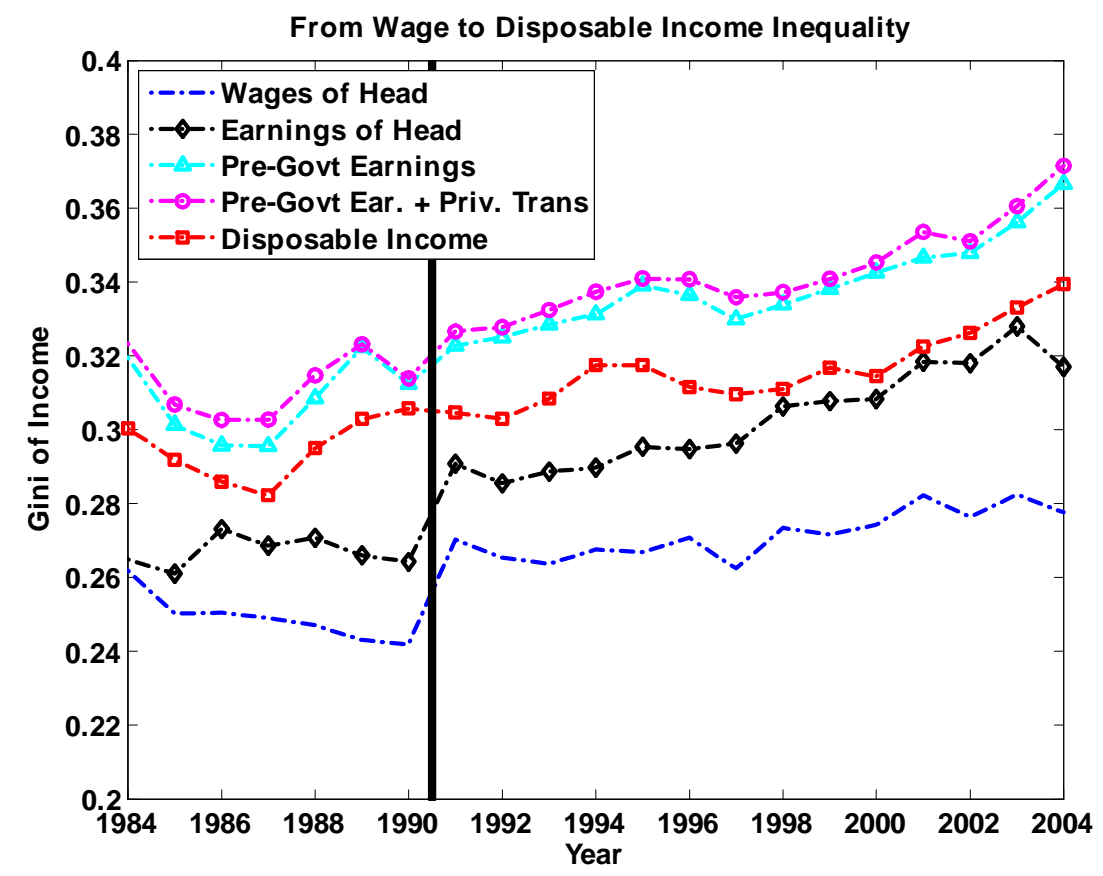

Figure 12: From Wage Inequality to Disposable Income Inequality: Gini Coefficients

changes), the variance of four logged income measures: household earnings including private transfers, the same measure net of taxes, the same measure including public transfers and finally disposable income. The figure paints a sharp picture about the relative importance of taxes versus public transfers for shaping income inequality trends. While the income tax system plays an important role in curbing the substantial increase in earnings inequality starting in the mid-1990, public transfers seem to play a substantially larger role in insulating disposable income inequality from much of the increased inequality in market earnings (again note that the line that includes transfers does not subtract taxes from earnings). ${ }^{40}$

\footnotetext{
${ }^{40}$ Public transfers are defined as the sum of individual public transfers - student grants, maternity benefits, unemployment benefits, unemployment assistance, subsistence allowance and transition pay - over all individuals in the household, plus household benefits - housing allowances, child benefits, nursing care insurance, direct housing subsidy , subsistence assistance, support for special circumstances, social assistance for elderly and un-
} 


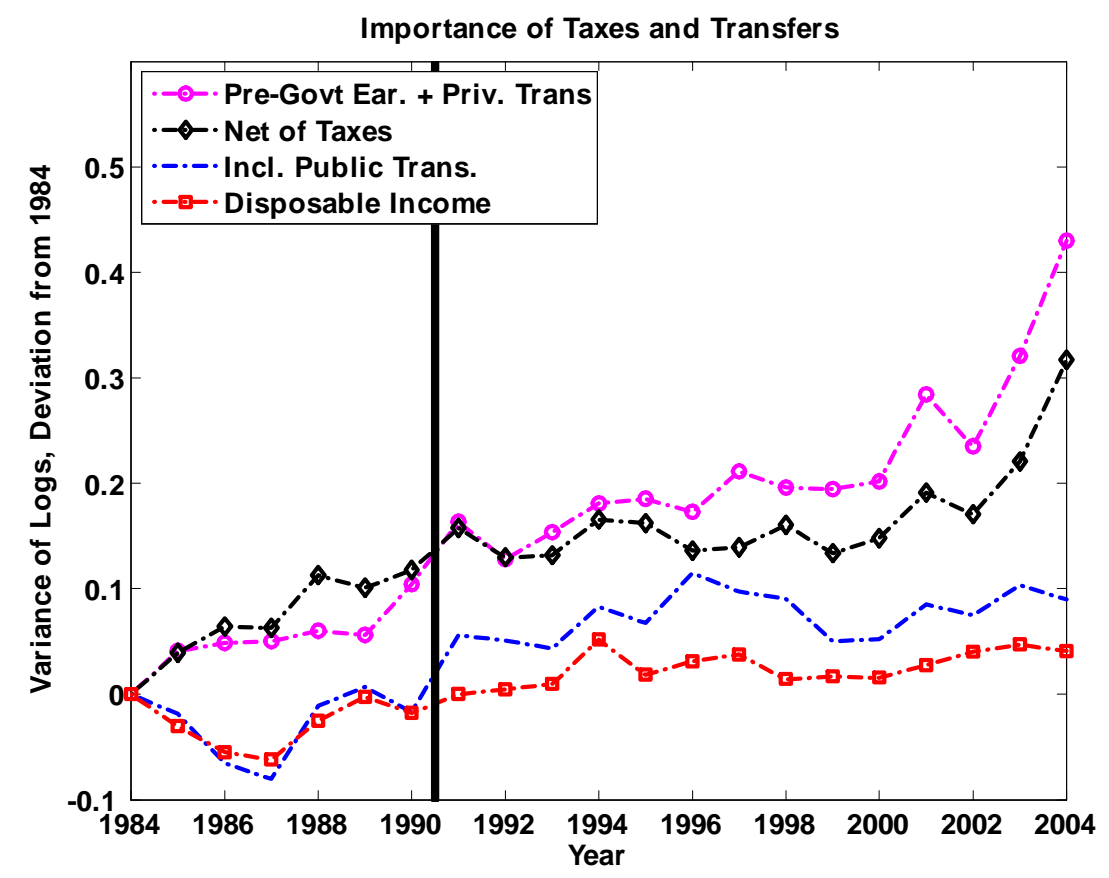

Figure 13: The Importance of Taxes and Transfers

While it is difficult to speculate about the future evolution of inequality, given the documented importance of public transfers in figure 13 and the substantial reforms of the public transfer system through the Agenda 2010 in 2003 it is plausible that future increases in inequality in market incomes will translate more strongly into inequality of disposable incomes than was the case in the previous two decades.

\subsection{Consumption Inequality}

While income inequality trends are interesting in their own right, to the extent that households can (self-) insure against at least temporary fluctua-

employment benefit II (welfare). To this we add social security benefits and pensions, i.e. the sum of old-age, disability, and widowhood social security pensions. This include payments of the German Pension Insurance (GRV), Miner's social Insurance (Knappschaft), Civil Servant Pension (Beamtenpension), War Victim Benefits (Kriegsopferversorgung), Farmer's Benefits and accident pension (GUV). 
tions in income, the cross-sectional consumption distribution (together with the distribution of hours worked) may be more informative about the crosssectional distribution of economic welfare than the corresponding income distribution. We therefore now document consumption inequality trends for Germany in the last 25 years.

Unfortunately the GSOEP, the data set we used so far for wages, earnings and income inequality, contains no useful information about household consumption. We therefore turn to the EVS, a household consumption survey conducted only once every five years. While both GSOEP and EVS are constructed with the explicit goal of being representative of the German population and while we employed exactly the same sample selection criteria on both data sets, we cannot overcome the problem that the timing of income observations from GSOEP and consumption inequality observations from EVS differ. In particular, for the period prior to German unification we have only one year (1988) for which both GSOEP income and EVS consumption inequality data are available.

With these caveats in mind we now display, in figures 14 and 15, the basic trends in consumption inequality from the EVS. These figures are the counterparts to the household earnings inequality trends displayed in figures 9 and 10. Figure 14 contains the decomposition of the cross-sectional consumption dispersion into parts predictable by household size and other observables, whereas figure 15 displays consumption inequality trends for various inequality measures.

From the first panel of figure 14 we learn that, in contrast to earnings, a much larger share of the log-variance in household consumption is explained by differences in household size. While for household earnings equivalization by household size hardly changed levels and trends of earnings dispersion, for consumption household size accounts for about $28 \%$ of the overall dispersion in household consumption (with its importance significantly growing over time). ${ }^{41}$ Furthermore, the fraction of the variance of equivalized log-consumption inequality accounted for by other observable household characteristics (apart from household size) is significantly smaller than for earnings. Among the regressors, household composition has by far the most explanatory power for consumption (for earnings it was education), whereas

\footnotetext{
${ }^{41}$ This in turn is due to the fact that household size and household consumption are much more strongly (and increasingly so, over time) positively correlated than is household size and household earnings.
} 


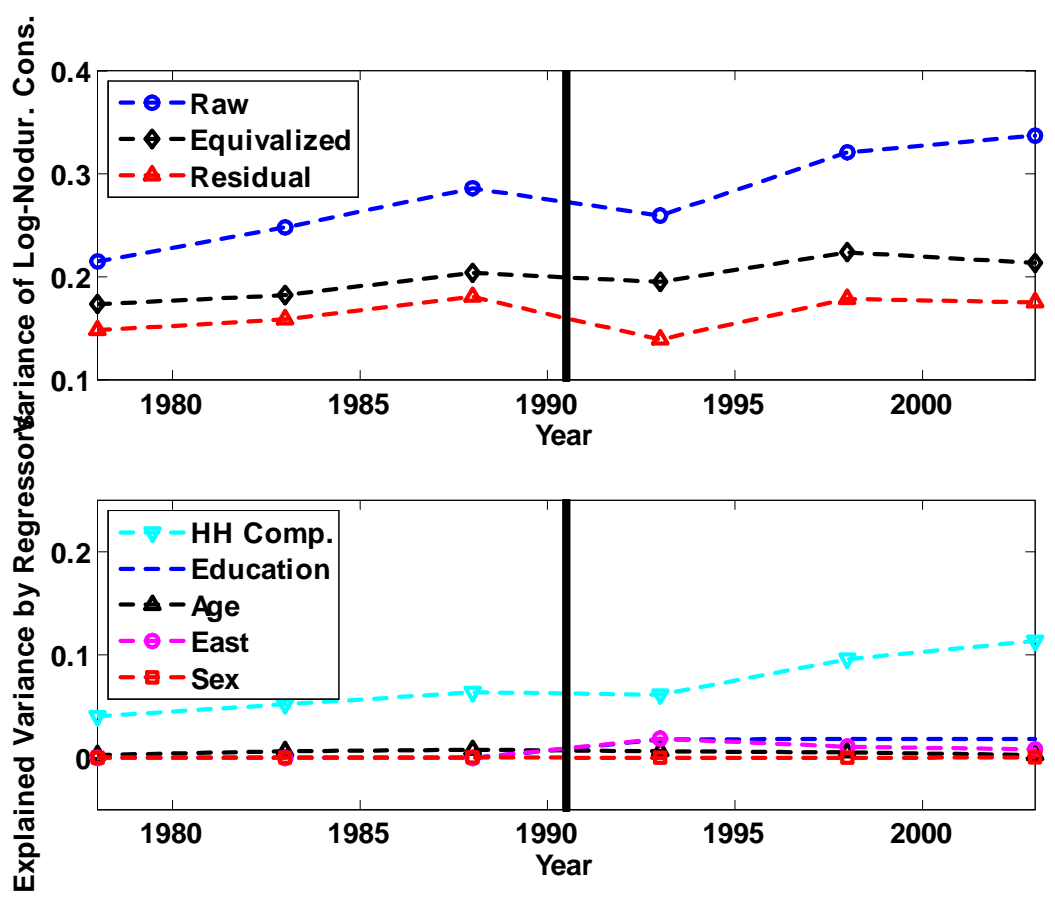

Figure 14: Decomposition of Consumption Inequality

the fraction of the equivalized household consumption variance explained by household age and gender of the head is negligible. The fact that household age is significantly more important for explaining income than consumption is not surprising from a life-cycle theoretic perspective, as long as households have access to some mechanisms (such as financial markets) that allow them to smooth their consumption. The East dummy, from 1993 on, explains a noticeable, but declining part of cross-sectional consumption inequality. Finally note that we have detailed information about educational attainment in the EVS only from 1993 onwards, so that this regressor plays no role prior to 1993 by construction. Afterwards it is the second most important determinant of consumption dispersion, although its importance is not nearly as large as that for earnings.

Turning to levels and trends in consumption inequality we first note that both unadjusted, and to an ever larger extent equivalized consumption are significantly more equally distributed than is the corresponding measure of household disposable income (which in turn is significantly more equally dis- 
tributed than household pre-tax earnings, see figure 11). Second, consumption inequality did rise between 1978 and 1988 in West Germany, especially between 1983 and 1988, fell between 1988 and 1993 and then displayed an increase again in post-unification Germany between 1993 and 2003. The size of these changes over time differ somewhat depending on the extent to which we control for the effects of observables on household consumption, but they are rather small in general. Focusing on equivalized household consumption we find an increase in the log-variance of two points between 1978 and 1988, a decline by one point from 1988 to 1993 and an increase of two points since then. ${ }^{42}$
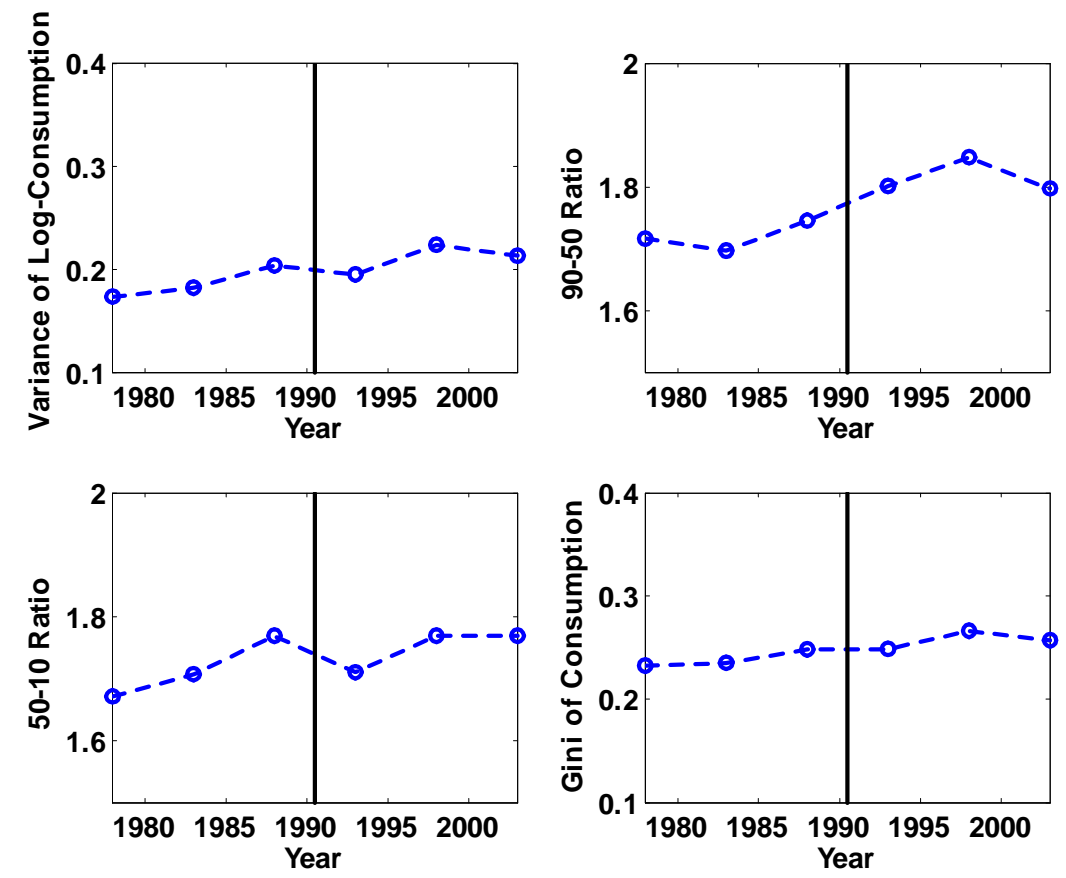

Figure 15: Trends in Non-Durable Consumption Inequality

\footnotetext{
${ }^{42}$ Note that the EVS changed the frequency at which consumption expenditures are collected from annual to quarterly periods from 1993 to 1998 . While this should have the strongest impact on the cross-sectional dispersion of consumption expenditures for items bought infrequently, such as consumer durable goods, which are not included in our nondurable consumption measure, we cannot exclude the possibility that part of the change in consumption inequality between 1993 and 1998 is due to this change in sample design.
} 
As figure 15 displays, other inequality statistics paint a similar picture: a very modest upward trend in consumption inequality with a small decline when the East German sample enters between 1988 and $1993 .^{43}$

Overall, the rather flat trend of consumption inequality coincides rather well with the similar trend observed for disposable household income inequality. In figure 16 we plot our various measures of inequality jointly for equivalized nondurable consumption and equivalized disposable income, both from GSOEP and EVS data. While disposable income is somewhat (and significantly so at the lower end of the distribution) more unequally distributed than is consumption ${ }^{44}$, the inequality trends (or lack thereof) line up rather well between the two variables. To make sure that this is not an artefact of using two different data sets for income and consumption, figure 16 includes trends of disposable income inequality as measured from the EVS. The fact that disposable income and consumption inequality display very similar trends is robust to using EVS income data (and thus robust to using exactly the same sample of households for measuring both consumption and income inequality).

\subsection{Wealth Levels and Wealth Inequality}

So far we have documented that while wage and earnings (and to a lesser extent, hours) inequality have increased in post-unification Germany after showing a fairly stable trend in the pre-unification years, the increase in aftertax income and consumption inequality has been rather modest. We finally investigate whether wealth inequality shares the same trends as earnings or consumption/disposable income. Before turning to the inequality statistics we first display trends for average net wealth (expressed as a ratio to income). These statistics are useful as calibration targets for macroeconomic models

\footnotetext{
${ }^{43}$ Due to the 5 year intervals between observations the inclusion of the East sample in 1993 may, but need not explain the temporary drop in consumption inequality. Splitting the sample between East and West German households we do observe, however, that consumption was significantly more equally distributed in the East in 1993 than in the West (and average consumption was only slightly lower in the East than in the West), thus potentially explaining why overall consumption inequality dropped in 1993. By 2003 consumption inequality in the East had caught up almost to West German levels. See section 7 for further details on this point.

${ }^{44}$ See the 50-10 ratio and the variance of logs, which puts more emphasis on the lower end of the distribution than the Gini coefficient.
} 

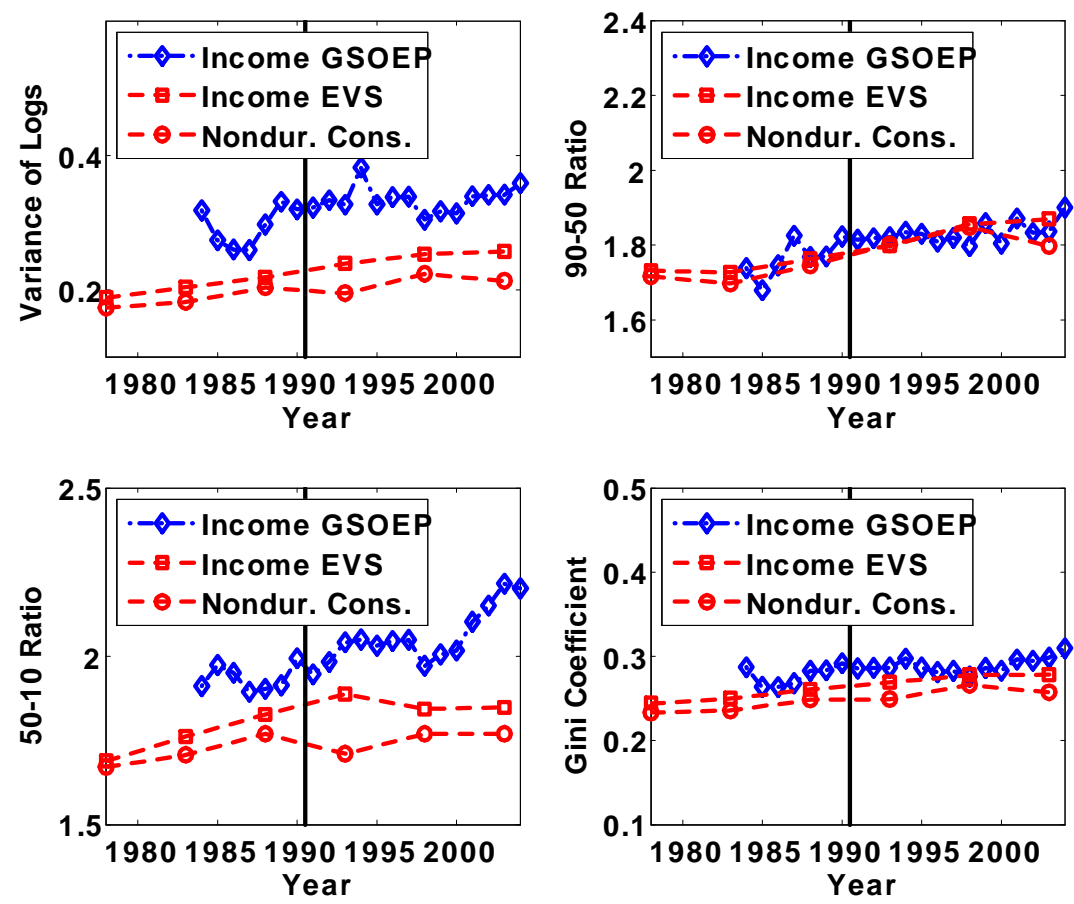

Figure 16: From Disposable Income to Consumption Inequality

as the amount of aggregate wealth in the economy determines how effectively households can self-insure against idiosyncratic risk through precautionary saving (see e.g. Storesletten et al., 2004). In the two top panels of figure 17 we display the ratio between net financial wealth and disposable income, as well as the same ratio for net total wealth (which in addition to net financial wealth includes net wealth in real estate). Two main observations stand out. First, German households hold most of their net wealth in real estate, rather than financial wealth. Roughly speaking, $70 \%$ of net worth of Germans comes in the form of real estate, with that fraction falling somewhat over time. ${ }^{45}$ Second, the wealth to income ratio has increased fairly significantly over time, from about 3 to 3.5 in the last 25 years. This happened despite the fact that between 1988 and 1993 the East German sample entered the EVS, and average wealth in the East was substantially lower than in the West, the reason being that disposable income also was substantially lower

\footnotetext{
${ }^{45}$ This is even more remarkable when noting that only about $50 \%$ of Germans own real estate.
} 
in the East. As a result, the wealth to income ratio did not increase between 1988 and 1993; it did increase for West Germans but this increase is offset by the composition effect of the East German households entering the sample.
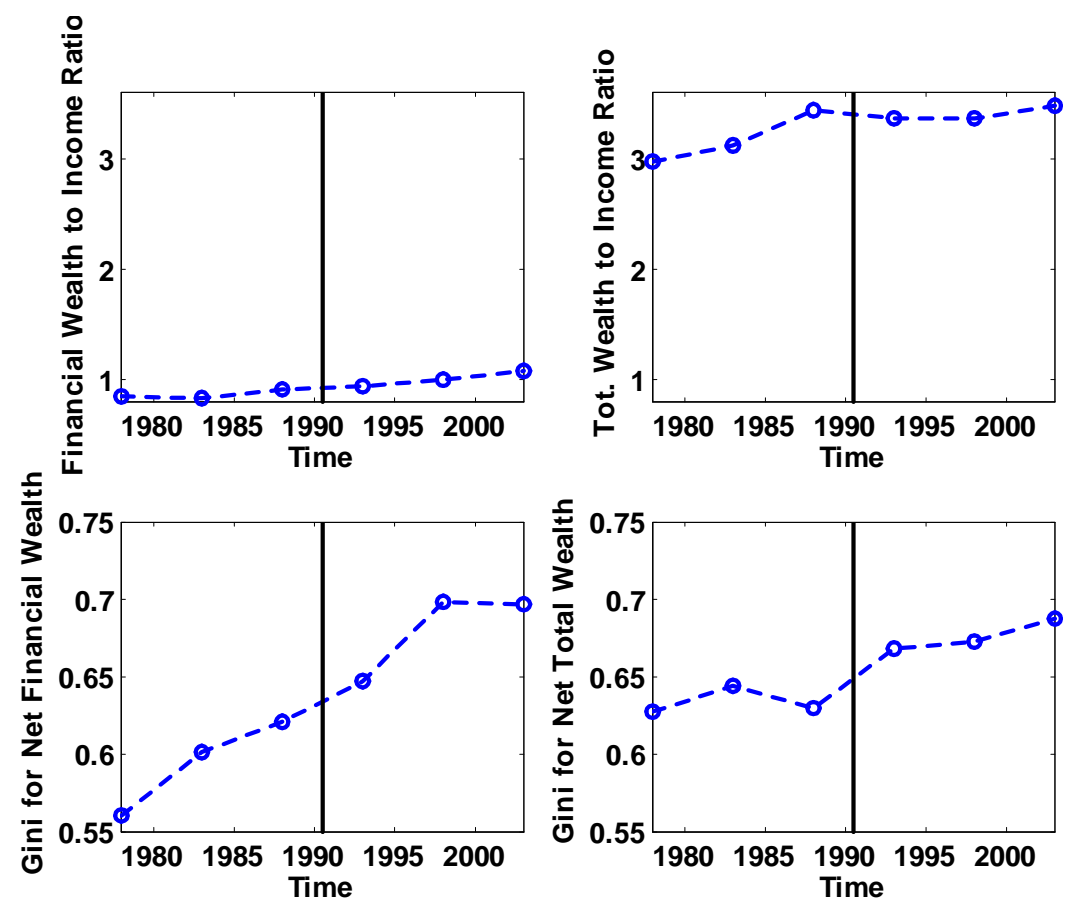

Figure 17: Trends in Wealth Inequality

The bottom two panels of figure 17 show that while average wealth holdings have increased, wealth inequality has done so, too. We measure wealth inequality by the Gini coefficient of household equivalized wealth, in order to account for the fact that a non-negligible fraction of households reports zero or negative net worth. The fraction of households reporting zero or negative wealth increased from $6.5 \%$ in 1978 to $10.5 \%$ in 2003, while the fraction of those households with negative wealth increased from $3.3 \%$ to $5.5 \%$. The increase in total wealth inequality is concentrated between 1988 and 1993 and is partially due to the difference in wealth levels between East and West Germans in 1993. However, even within West German households a modest increase in wealth inequality between 1988 and 1993, and after 1993, occurred. Overall the wealth Gini coefficient for total wealth has increased by 
6 points, from 0.63 to 0.69 . As a point of comparison, the corresponding increases in disposable income and consumption inequality (all measured from the EVS) are 3.4 points and 2.4 points, correspondingly. Thus the increase in wealth inequality, while slightly larger overall due to the larger composition effect in 1993 from the entering East German sample, are of comparable magnitude and timing than those for disposable income and consumption inequality. ${ }^{46}$

On the other hand, wealth inequality in financial assets has increased much more rapidly. Financial wealth is now slightly more unequally distributed than total wealth, while its Gini in 1978 was seven points lower than that of total wealth. A large part of these trends is due to differential trends in the prices of houses and stocks in Germany. The level of real estate wealth has essentially not increased, in real terms, partially because there was virtually no appreciation of house prices during the sample period (very much in contrast to most other industrialized countries). At the same time the prices of financial assets (relative to the CPI) have increased substantially. Consequently, at constant portfolio allocations one would expect increased inequality in financial wealth (with those holding assets whose prices appreciated gaining disproportionately) but no change in housing wealth inequality. This is exactly what the wealth inequality data display.

\section{Inequality Trends over the Life Cycle}

So far we have documented how inequality in Germany has changed over time. In order to empirically inform structural macro models that have an explicit life cycle structure, in this section we discuss how inequality in income and consumption evolves over the life cycle. While for the U.S. empirical studies documenting these facts exist, ${ }^{47}$ the evidence from our German data

\footnotetext{
${ }^{46}$ Also note that the level of wealth inequality is significantly lower than that in the U.S., even after German reunification. So is the (still substantial) share of households with zero or negative net worth.

${ }^{47}$ See Deaton and Paxson (1994), Storesletten et al. (2004) or Heathcote et al. (2005), among others.
} 
sources is new, to the best of our knowledge. ${ }^{48} 49$

In figure 18 we plot the variance of logs of four variables against age: wages, earnings equivalized by household size, disposable income equivalized by household size (all from the GSOEP), and consumption corrected by household size (from the EVS). In order to generate these plots one has to take a stand on the importance of time and cohort effects. Since time, age and birth year are perfectly collinear, we cannot separately identify age, time and cohort effects. Therefore we derive the age-inequality effects under two different assumptions about the presence of time and cohort effects, and plot them jointly in the figure. We implement age, cohort and time effects (if present) by a full set of dummies, and plot the age profile in deviation from the age $25-29$ values.

The first observation we make from figure 18 is that the choice of whether to control for time or for cohort effects is an important one. For all variables under study the increase in intra-cohort inequality over the life cycle is substantially more pronounced with cohort effects present than in the specification that includes only time effects. ${ }^{50}$ These differences are quantitatively important: for wages and consumption life cycle inequality, as measured by the variance of logs, increases by about 7-9 points more with cohort than with time effects; for earnings the difference is 40 points.

Second, we observe that wages, disposable income and consumption display a monotonic increase in inequality as a cohort ages. However, the overall increase in inequality is rather small over the life cycle, certainly when compared to similar figures for the U.S. The log-variance for wages increases by 7 points with time effects and 16 points with cohort effects between age groups of 25-29 and 60-64. The same statistic for disposable income remains flat (time effects) and rises by 8 points (cohort effects), and for consumption rises by 7 points (time effects) and 13 points (cohort effects).

The life cycle inequality profile for equivalized earnings, on the other hand displays substantial relative inequality among the 25-35 year old households,

\footnotetext{
${ }^{48}$ For this exercise we only use the West German sample in order to not contaminate our analysis by the unbalanced nature of the panel that the inclusion of the East German sample constitutes.

${ }^{49} \mathrm{~A}$ very recent working paper by Bayer and Juessen provides similar evidence for wages and compares the life cycle inequality trends in Germany to those in the US and UK. Their findings for Germany line up well with ours.

${ }^{50}$ Heathcote et al. (2005) find exactly the same pattern for the U.S. and argue for the specification with time effects.
} 

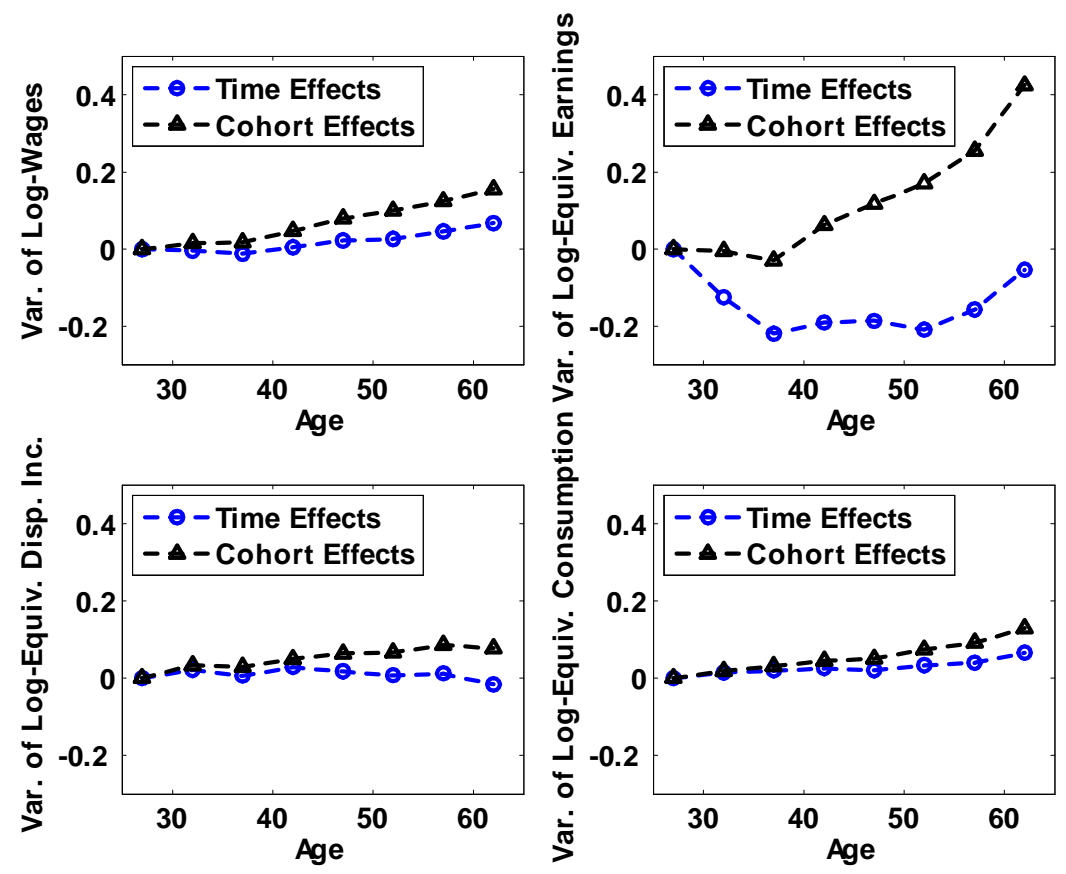

Figure 18: Life Cycle Inequality Facts

a decline towards middle ages, and then a substantial increase after age 40 . The U-shaped pattern of life cycle inequality for earnings is especially pronounced in the absence of cohort effects; but even controlling for these life cycle inequality falls until age 35-39. Part of the high relative earnings inequality among younger cohorts is the noticeable incidence of unemployment among these age groups. ${ }^{51}$ Furthermore, especially for the youngest cohort a fair share of individuals are still in vocational training, which is compensated much worse than regular work, partially because an important part of the time spent in these jobs is devoted to human capital accumulation rather than production. Finally, students in Germany typically do not leave university until their middle to late twenties, adding another group that has very

\footnotetext{
${ }^{51}$ Unemployed individuals with recorded zero wages do not enter the sample on which life cycle wage inequality is computed. On the other hand, these individuals enter the earnings sample if other household members have positive earnings. Notice that there is no initial decline in the life cycle inequality plot for wages.
} 
low (but typically not zero, due to part-time jobs) earnings. ${ }^{52} 53$

Taken jointly, the life cycle inequality pictures confirm our time series observations: over the life cycle earnings inequality increases more substantially than wage inequality, but this increase does not translate into a correspondingly large increase in disposable income or consumption inequality. These findings again suggest, now from a life cycle perspective that over the sample period the German tax and transfer system has acted as an important factor mitigating the rise in economic inequality.

\section{A Stochastic Wage and Earnings Process for Germany}

Our analysis so far used exclusively cross-sectional information from the EVS and the GSOEP to document inequality trends over time and over the life cycle. In this section we document results from estimating a stochastic wage and earnings process from the GSOEP, explicitly making use of the long panel dimension available in the GSOEP. We view this exercise as interesting for two independent reasons. First, stochastic wage or earnings processes of the form we estimate are a crucial input into quantitative models with household heterogeneity, independent of whether these models contain an explicit life cycle structure or not. Second, the results from our panel estimation may help us to further interpret the trends in wage and earnings inequality in the cross section that we have documented above in section $4 .^{54}$

\footnotetext{
${ }^{52}$ While U.S data may also display the U-shaped age-earnings inequality profile that we document here (see e.g. figure 3, panel 3 of Huggett et al., 2004) the decline sets in much earlier in the life cycle (it is typically complete by age 25) and is not nearly as severe as in our German data. On the other hand, the phenomena mentioned in the main text (vocational training, youth unemployment, late entry into the labor market by students) are not very prevalent in the U.S. either.

${ }^{53} \mathrm{~A}$ U-shaped age-inequality profile can also emerge if the stochastic process for earnings has a fixed effect and a random growth component, as recently advocated by Guvenen (2007). If the random growth component is negatively correlated with the fixed effect, the cross-sectional earnings variance of a cohort can first fan in and then fan out (depending on the size of the correlation and the variance of the random growth component).

${ }^{54}$ Biewen (2005) estimates a slightly different stochastic process for GSOEP equivalized disposable income data from 1990 to 1998, separately for West and East German households. Because of the differences in the economic variable used and the process being estimated, his results cannot be directly compared to ours.
} 
As many authors in the literature (e.g. Meghir and Pistaferri, 2004) we estimate a parsimonious stochastic process for wages and earnings that allows for temporary and permanent shocks, and allows the size of the shocks to vary over time. More precisely we estimate the statistical model

$$
\ln y_{i, t}=\mathbf{x}_{i, t}^{\prime} \boldsymbol{\psi}_{t}+z_{i, t}
$$

where here $y_{i, t}$ stands either for wages of individual $i$ or labor earnings of household $i$ at time $t$. The vector of controls $\mathbf{x}_{i, t}$ includes year dummies, dummies for family composition, a quartic polynomial in the age of the household head, education dummies, and an East-West dummy. ${ }^{55}$ All regressors have time-varying coefficients $\boldsymbol{\psi}_{t}$. The stochastic component of wages or earnings $z_{i, t}$ is assumed to follow the process

$$
z_{i, t}=p_{i, t}+\varepsilon_{i, t}, \text { with } \varepsilon_{i, t} \sim N\left(0, \sigma_{\varepsilon, t}^{2}\right)
$$

where the persistent component of the process $p_{i, t}$ is assumed to take the form of a random walk

$$
p_{i, t}=p_{i, t-1}+\eta_{i, t}, \text { with } \eta_{i, t} \sim N\left(0, \sigma_{\eta, t}^{2}\right) .
$$

We assume that both the permanent and the transitory shock $\eta_{i, t}$ and $\varepsilon_{i, t}$ are i.i.d. across agents (individuals or households) and time. As highlighted above we allow both the variance $\sigma_{\varepsilon, t}^{2}$ of the transitory component and the variance $\sigma_{\eta, t}^{2}$ of the permanent shock to be time-varying.

This process is typically estimated by a minimum distance estimator that selects estimates for $\left(\sigma_{\varepsilon, t}^{2}, \sigma_{\eta, t}^{2}\right)$ together with $\sigma_{p_{0}}^{2}$ in order to minimize the weighted sum of squared distances between selected moments implied by the statistical model and the corresponding moments in the data. The moments commonly used are either autocovariances in levels, $\operatorname{cov}_{t}\left(z_{i, t}, z_{i, t-j}\right)$ or autocovariances in first differences $\operatorname{cov}_{t}\left(\Delta z_{i, t}, \Delta z_{i, t-j}\right)$, both of which can be used to estimate the variances of interest. Note that as long as the statistical model is not mis-specified, using either set of moments should deliver similar results. ${ }^{56}$ Unfortunately the results vary substantially across the moments being used, thus below we document results based on both sets of moments.

\footnotetext{
${ }^{55}$ We repeated our estimation with data from only West German individuals/households and found results very similar to the ones reported here.

${ }^{56}$ For further details on the estimation procedure using first differences, see the instructions of the overall project, Krueger et al. (this issue). The U.S. paper (Heathcote et al., this issue) explains in more detail how the model is estimated when using level moment
} 
Since our estimates derived from levels appear to be more plausible based on the evidence on the level of wage and earnings dispersion as well as their trend over the life cycle, we present them first. The top panel of figure 19 plots, against time, the variance of transitory and permanent wage shocks, and the bottom panel does the same for earnings. Note that, as before, the wage of a household refers to the wage of the household head. We make several observations. First transitory shocks are significantly larger than permanent shocks (but note that the latter accumulate over a person's life). Second, the magnitude of transitory shocks has no time trend; it is completely flat for wages and increases and then declines to its original level for household earnings. Third, the size of permanent shocks, while constant and small in the pre-unification years, has increased since, with the increase particularly pronounced since 1998 for earnings. For wages, $\sigma_{\eta}^{2}$ is larger on average after 1991 than before, but permanent wage shocks remain fairly small. Fourth, the shocks to wages are significantly smaller than those to household earnings.

These findings are consistent with the cross-sectional inequality facts we have presented so far, and they also square well with the dynamics of inequality over the life cycle (at least if one focuses on the specification with cohort effects present). In terms of levels, inequality in household earnings is substantially larger than that in wages. Viewed in light of the estimates presented here part of this difference is due to the fact that wages are subject to smaller shocks than household earnings. For changes over time, inequality in wages and earnings did not rise in West Germany prior to unification, and the shocks to the stochastic part of the households wages and earnings have not become larger. The increase in inequality since then, most pronounced since 1998 and more pronounced for earnings than for wages can, at least in part, be attributed to larger permanent shocks, whereas temporary shocks remained constant. ${ }^{57}$ Inequality over the life cycle rises very slowly for wages and more substantially (but still slowly, compared to the U.S. case) for earn-

conditions; we follow their approach closely. We deviate form their approach in one important dimension. They target autocovariances that are allowed to differ by year, lag and age of the households whereas we only target covariances indexed by year and lag, in effect averaging over households with different ages. The advantage of this approach is that each covariance we target is precisely estimated in the data (as cell sizes are large), the disadvantage is that we, relative to Heathcote et al., have fewer moments for the estimation and thus larger standard errors for the estimated variances.

${ }^{57}$ Of course our empirical results beg the question why wage shocks have become more permanent, and the permanent shocks have become larger. 
ings, which is consistent with permanent shocks being generally small but relatively more important for earnings than for wages. We take the fact that the estimation of stochastic wage and earnings processes paint, broadly, the same picture as our analyses of inequality over time and the life cycle as reassuring for our overall results.

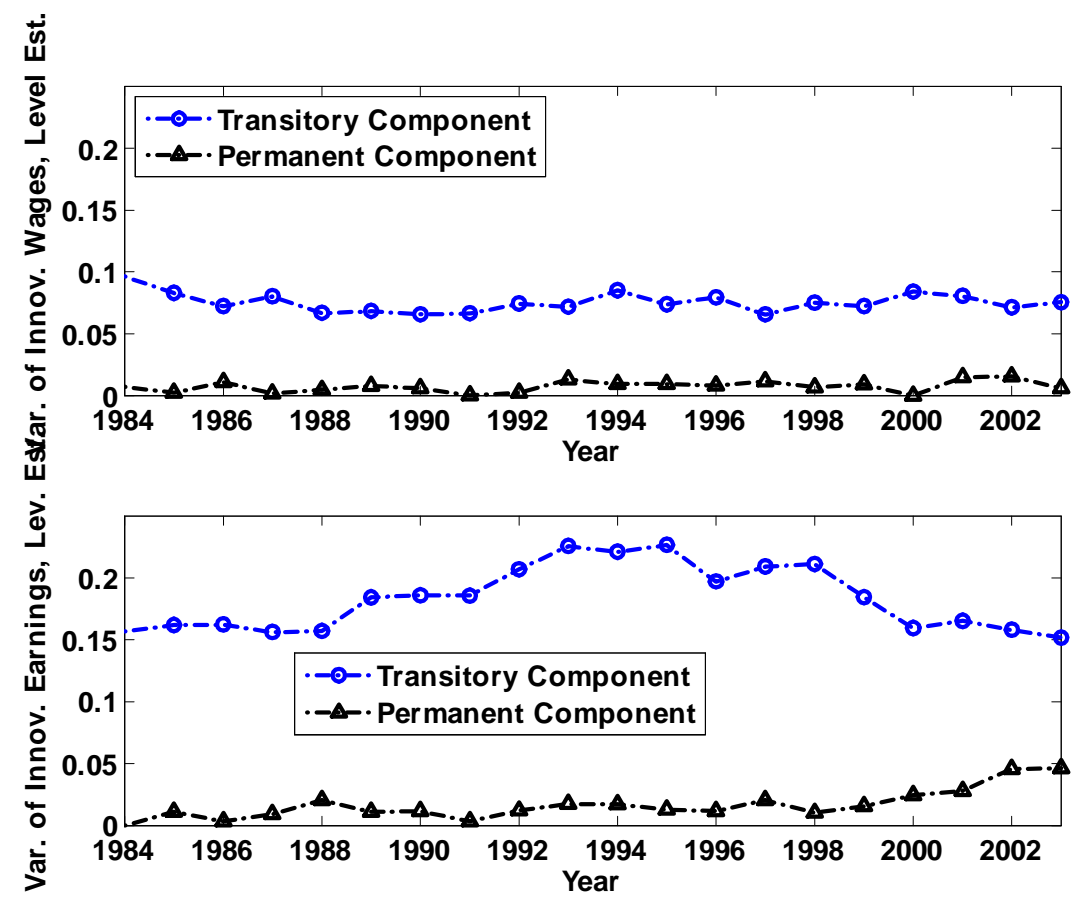

Figure 19: Stochastic Wage/Earnings Processes: Estimation in Levels

Unfortunately the results based on the moment conditions in first differences are not entirely consistent with the results displayed so far. In figure 20 we plot the estimates of the variances of the transitory and permanent shocks based on the moments in first differences. As with estimates based on levels the size of transitory shocks displays essentially no time trend whereas permanent shocks are larger in the post-unification than in the pre-unification period. Thus, as before the ratio $\sigma_{\eta, t}^{2} / \sigma_{\varepsilon, t}^{2}$ is increasing over time (the ratio declines slightly for earnings in the very last years of the sample). Also as before, the shocks to household earnings are larger than those to wages.

The main divergence in results between using level and first difference moments is the size of permanent relative to transitory shocks. Permanent 


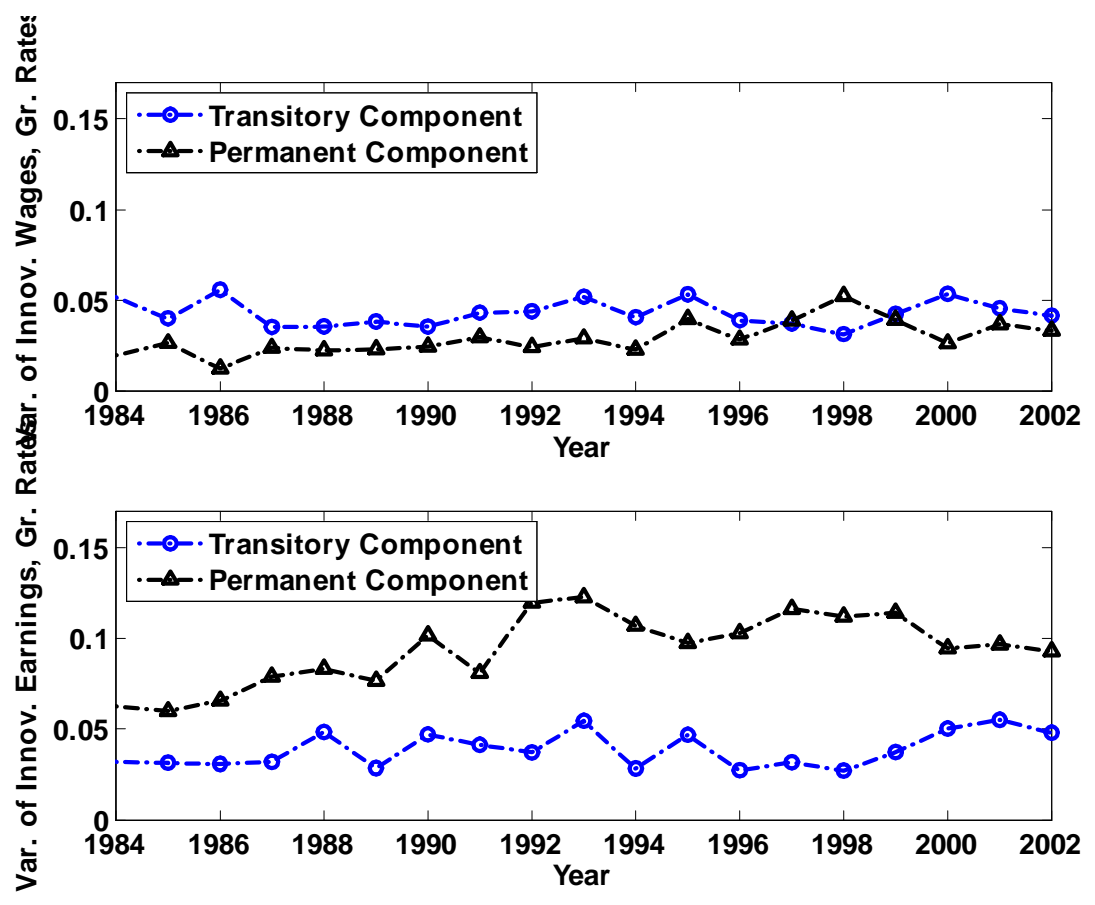

Figure 20: Stochastic Wage/Earnings Processes: Estimation in Growth Rates

shocks are an order of magnitude larger when estimated based on first differences, and transitory shocks are somewhat smaller. As point of comparison, the average (over time) variance of permanent shocks is $\sigma_{\eta}^{2}=0.016$ when estimated using levels, but $\sigma_{\eta}^{2}=0.094$ when using first differences. The latter appears to be unreasonably large. For example, a completely homogeneous cohort of households that starts receiving earnings shocks at age 27 following the process we specified would display an increase in the cross-sectional variance of log earnings of 3.29 from age 27 to age 63 with the estimates derived from first differences. This compares with an increase of 0.56 based on the estimates using levels and with an increase of 0.43 in the data, see figure 18, upper-right panel. ${ }^{58}$ In addition, the level of cross-sectional wage and

\footnotetext{
${ }^{58}$ While the estimation of the stochastic processes controls for observables of households and the life cycle inequality plots do not, it seems implausible to us that the reduction in inequality of earnings due to the reduction in the dispersion of observables over the life cycle is so massive that it could counteract the large increase in life cycle earnings inequality implied by the size of the permament shock as estimated on first differences.
} 
earnings dispersion implied by the first difference estimates is implausibly large, relative to what we have documented in section 4. Therefore, based on the overall findings documented in the paper, we view the level estimates as a more reasonable description of the amount and persistence of wage and earnings risk German households face. ${ }^{59}$

\section{The German Reunification as a Large Ex- ogenous Shock}

So far, with a few exceptions we have treated data of households living in East Germany symmetric to West German households from the time the East households joined the GSOEP and the EVS data. In this section we decompose some of the inequality trends documented above into inequality changes within the East, within the West and changes in inequality between the Eastern and the Western parts of the country. Since the EVS only reports the current residence, not the residence at reunification, we rely on the current residence for this decomposition.

Note that between 1991 and 2006, net East-West migration amounted to 1.45 million people, with gross flows of 2.45 million people migrating from East to West, and 1 million people the other way round. ${ }^{60}$ The population in East Germany fell from 14.5 million at the end of 1991 to 13.2 million people at the end of 2006, with the West German population grew from 59.7 million to 62.9 million people. ${ }^{61}$ Migrants are clearly a self-selected group, with young and increasingly more educated people exhibiting a higher propensity to migrate from East to West (Fuchs-Schündeln and Schündeln, 2009). This

\footnotetext{
${ }^{59}$ Of course this conclusion leaves the important issue of model misspecification open. If the model is correctly specified using both moment conditions should give similar estimates (identical estimates asymptotically, and we find it hard to believe that small sample bias explains the huge deviations among the estimates). Thus the results are suggestive of the fact that the simple permanent vs. transitory shock decomposition employed here is insufficient to describe wage and earnings shocks faced by German households. Bayer and Juessen (2009) estimate a process similar to ours but allow the persistent shock to be less than fully permanent. They estimate a persistence parameter for wages in the order of magnitude of 0.9 .

${ }^{60}$ These numbers count people going back and forth between both parts of Germany several times.

${ }^{61}$ These numbers exclude (East and West) Berlin. The population in Berlin decreased slightly between 1991 and 2006, from 3.45 million to 3.4 million.
} 
should be kept in mind when interpreting the decomposition results.

One of the attractive features of the use of variance of a variable as inequality statistic is that it can be decomposed into within-group and betweengroup inequality. For the German case the unique event of the reunification determines as the most interesting characteristic of a group the region of residence, that is, the East-West distinction. We can write the variance of the $\log$ of a variable $y$ as ${ }^{62}$

$$
\begin{aligned}
\sigma^{2}= & \operatorname{Var}\left(\log \left(y_{i}\right)\right)=n_{\text {East }} \operatorname{Var}_{\text {East }}\left(\log \left(y_{i j}\right)\right)+n_{\text {West }} \operatorname{Var}_{\text {West }}\left(\log \left(y_{i j}\right)\right) \\
& +\left[n_{\text {East }} \mu_{\text {East }}^{2}+n_{\text {West }} \mu_{\text {West }}^{2}-\mu^{2}\right]
\end{aligned}
$$

where

$$
\begin{aligned}
n_{j} & =\frac{N_{j}}{N} \\
\overline{\log y_{j}} & =\frac{1}{N_{j}} \sum_{i \in j} \log \left(y_{i}\right) \equiv \mu_{j} \\
\overline{\log y} & =\frac{1}{N} \sum_{i} \log \left(y_{i}\right) \equiv \mu \\
\operatorname{Var}_{j}\left(\log \left(y_{i j}\right)\right) & =\sum_{i \in j} \frac{1}{N_{j}}\left(\log \left(y_{i}\right)-\overline{\log y_{j}}\right)^{2} \equiv \sigma_{j}^{2}
\end{aligned}
$$

and $N$ is the number of population. Thus the inequality of a variable of interest can be decomposed into inequality in the East, inequality in the West and inequality between the East and the West (the last term in brackets in equation (3)). Note that if East and West German data were drawn from the same population distribution, then $\mu_{\text {East }}^{2}=\mu_{W e s t}^{2}=\mu^{2}$ and the last term would be zero. If, on the other hand, there is dispersion in the means between East and West (as is the case for all economic variables we are interested in), then the last term is positive and contributes to overall inequality in Germany.

This decomposition can now be used to disaggregate the trend in inequality into its underlying sources. In particular, the change in measured

\footnotetext{
${ }^{62}$ For ease of reading, we suppress a time subscript.
} 
inequality of a variable from one period to the next is given by

$$
\begin{aligned}
\Delta \sigma_{t}^{2}= & n_{\text {East }, t} \Delta \sigma_{\text {East }}^{2}+n_{\text {West }, t} \Delta \sigma_{\text {West }}^{2} \\
& +\Delta n_{\text {East }} \sigma_{\text {East }, t+1}^{2}+\Delta n_{\text {West }} \sigma_{\text {West }, t+1}^{2} \\
& +n_{\text {East }, t}\left[\Delta \mu_{\text {East }}^{2}-\Delta \mu^{2}\right]+n_{\text {West }, t}\left[\Delta \mu_{\text {West }}^{2}-\Delta \mu^{2}\right] \\
& +\Delta n_{\text {East }}\left[\mu_{\text {East }, t+1}^{2}-\mu_{t+1}^{2}\right]+\Delta n_{\text {West }}\left[\mu_{\text {West }, t+1}^{2}-\mu_{t+1}^{2}\right]
\end{aligned}
$$

The first term is the change in within-group inequality due to within region changes of variances, the second term is the change in within-group inequality due to changes in population shares between East and West, the third term is the change in between-group inequality due to changes in relative means between East and West, and the fourth term is the change in between-group inequality due to changes in the relative size of the household population between East and West. We will now use this decomposition for decomposing inequality trends into East versus West and within the two regions. ${ }^{63}$ Also note that this decomposition is particularly clean if the relative size of the groups remains roughly constant (that is $\Delta n_{j}=0$ ), since then

$$
\begin{aligned}
\Delta \sigma_{t}^{2}= & n_{\text {East }, t} \Delta \sigma_{\text {East }}^{2}+n_{\text {West }, t} \Delta \sigma_{\text {West }}^{2} \\
& +n_{\text {East }, t}\left[\Delta \mu_{\text {East }}^{2}-\Delta \mu^{2}\right]+n_{\text {West }, t}\left[\Delta \mu_{\text {West }}^{2}-\Delta \mu^{2}\right]
\end{aligned}
$$

In figure 21 we plot the variances of log wages for males, log household earnings, log equivalized disposable income (from GSOEP) and log equivalized consumption (from EVS) both for West Germany and East Germany, as well as Germany as a whole. Prior to 1991 (1993 for consumption in the EVS) the entire sample is composed of West German households, so the lines for West Germany and total Germany exactly coincide. From 1991 onward (1993 in the EVS) the East German sample enters, and, as shown above, the variance of wages, earnings, income and consumption in unified Germany equals the weighted sum of the region-specific log-variances, plus the dispersion in the log-means (not plotted here).

In Table I we display the results of the decomposition analysis for inequality of male wages, household earnings, disposable income and consumption (the latter two variables equivalized). In order to not let our results overly be influenced by high frequency fluctuations for the GSOEP variables we

\footnotetext{
${ }^{63}$ This decomposition is essentially the same as the one employed by Schwarze (1996) for the so-called Theil $I(0)$ inequality index.
} 

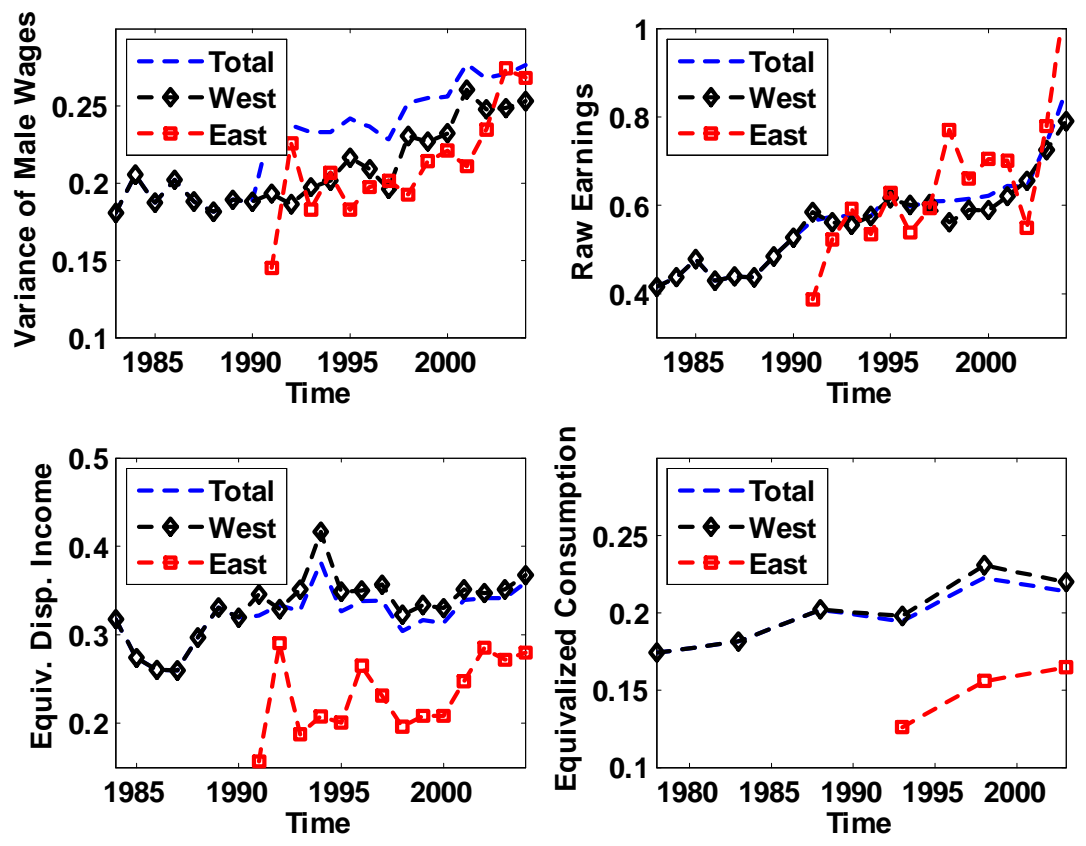

Figure 21: Variance of Wages, Earnings and Income in East and West Germany

average the cross-sectional variances over the last three years prior to unification, 1988-90 (and denote the averaged variance as $\left.\sigma_{1988}^{2}\right)^{64}$, we average the variances for the first three years after unification, 1991-93 (denoted as $\sigma_{1993}^{2}$ ) and we average the variances for the last three years in our survey (denoted as $\sigma_{2003}^{2}$ ). For the EVS we take the cross-sectional variance for the last year prior to unification (1988), the first year after unification for which data are available (1993) and the last year of the sample (2003). ${ }^{65}$

\footnotetext{
${ }^{64}$ This variance is computed on the sample of West German households only, as the East Germn households only enter the sample after the unification.

${ }^{65}$ The observations for $c / s$ from the EVS refer to 1988, 1993 and 2003, rather than 88-90, 91-93 and 2002-04. To compute the consumption variances and means in this table we used the regional weights from the EVS which make sure that the results are both representative in the former East and the former West. All previous results were based on national weights, assuring that the results are representative for the country as a whole. While the results of the previous analyses are not significantly affected by which weighting we use, in the decomposition analysis the fact that national weights do not assure that the appropriate share of Eastern Germans are present makes them inappropriate for the
} 
Table I: Variance Decomposition

\begin{tabular}{|l||r|r|r|r|r|}
\hline Variable & $w_{m}$ & $y^{L}$ & $y^{D}$ & $y^{D} / s$ & $c / s$ \\
\hline$\sigma_{1988}^{2}$ & 0.186 & 0.484 & 0.365 & 0.316 & 0.202 \\
\hline$\sigma_{1993}^{2}$ & 0.236 & 0.574 & 0.385 & 0.328 & 0.195 \\
\hline$\sigma_{E, 1993}^{2}$ & 0.185 & 0.501 & 0.331 & 0.212 & 0.126 \\
\hline$\sigma_{W, 1993}^{2}$ & 0.192 & 0.569 & 0.389 & 0.342 & 0.198 \\
\hline$\sigma_{E W, 1993}^{2}$ & 0.045 & 0.017 & 0.006 & 0.009 & 0.010 \\
\hline$\sigma_{2003}^{2}$ & 0.272 & 0.748 & 0.423 & 0.348 & 0.214 \\
\hline$\sigma_{E, 2003}^{2}$ & 0.260 & 0.803 & 0.422 & 0.279 & 0.165 \\
\hline$\sigma_{W, 2003}^{2}$ & 0.250 & 0.725 & 0.415 & 0.356 & 0.220 \\
\hline$\sigma_{E W, 2003}^{2}$ & 0.020 & 0.010 & 0.007 & 0.005 & 0.004 \\
\hline
\end{tabular}

Several observations stand out. First, as documented above, the increase in inequality in earnings is substantially larger than that of disposable income and consumption, directly after the unification and in the subsequent ten years. Second, initially wages, earnings, incomes and consumption are more equally distributed in the East than in the West. However, this fact is reversed a decade after the unification. With the exception of equivalized disposable income and consumption, inequality in the East has caught up, in fact slightly surpassed, that in West Germany. ${ }^{66}$ This is due to a strong increase in inequality in the East (even with respect to disposable income and consumption), and a noticeable, but much more modest increase in the West. Third, right after reunification there did exist substantial differences between East and West German means, especially for wages and earnings. Fourth, we observe some convergence in (male) wages and earnings (that is, in variables that do not contain taxes and transfers by the government) as well as equivalized consumption between the East and the West in the decade following German unification. ${ }^{67}$

To further decompose the changes in inequality between 1991-1993 and 2002-2004, we now display, in table II, the contributions that changes in

purpose, and we therefore switched to regional weights.

${ }^{66}$ Biewen (2001) measures the contribution of the decline in female labor force participation and rising unemployment on equivalized disposable income inequality in East Germany and finds that both factors contributed considerably to its increase between 1990 and 1995.

${ }^{67}$ Note that this convergence could partially be a result of migration. However, since individuals/households with high wages and incomes (or wage and income potentials), if they migrated, tended to migrate from the East to the West, we conjecture that migration was a negative force on convergence. 
inequality in the East (row 3), changes in inequality in the West (row 4), changes in the population shares (row 5) and changes in inequality between East and West (row 6) had on overall inequality. In order to interpret these contributions note that in our sample about one fifth of households live in the East, with that fraction falling somewhat by the end of the sample. Table II reinforces the finding that the East contributes a disproportionate (relative to the population) share of the increase in the overall variance, especially for the earnings and income variables. Furthermore, at least for wages, earnings and equivalized consumption some of the increase in within-region inequality is offset by a decline in between-region inequality. ${ }^{68}$

Table II: Decomposition of Change in Inequality

\begin{tabular}{|l||l|l|l|l|l|}
\hline Variable & $w_{m}$ & $y^{L}$ & $y^{D}$ & $y^{D} / s$ & $c / s$ \\
\hline$\Delta \sigma^{2}$ & 0.036 & 0.175 & 0.038 & 0.020 & 0.019 \\
\hline$n_{E} \Delta \sigma_{E}^{2}$ & 0.014 & 0.055 & 0.016 & 0.012 & 0.007 \\
\hline$n_{W} \Delta \sigma_{W}^{2}$ & 0.047 & 0.127 & 0.021 & 0.011 & 0.018 \\
\hline$\Delta n$ & -0.000 & -0.001 & -0.000 & 0.000 & 0.000 \\
\hline$\Delta \mu_{E, W}$ & -0.025 & -0.008 & 0.001 & -0.003 & -0.006 \\
\hline
\end{tabular}

\section{Conclusion}

This paper documents the evolution in inequality in Germany in the last twenty five years, a period that saw the German reunification in 1990. We show that, broadly speaking, inequality was rather stable in the years prior to the German unification. It rose, at impact, because a poorer sample from the East joined the West German data. After the reunification inequality in market wages and earnings rose both in the East and in the West, with a more pronounced increase in the East and some convergence between the two regions. On the other hand, the public tax and transfer system seems to have mitigated some of this inequality increase, with inequality in after

\footnotetext{
${ }^{68}$ Note that the last row measures both the effects of changes in relative log-means, as well as changes in the population shares receiving these relative means. Since the share of households living in the East (which has lower means) declines, one may observe "convergence" even without changes in the relative East-West means. For wages, the only variable for which $\Delta \mu_{E, W}$ is substantially negative, both effects are present: there is some convergence between mean log wages in the East and the West in the 10 years after the German unification, and the share of households residing in former West Germany increased by about two percentage points.
} 
tax-transfer household disposable income (and consumption) showing substantially less of an increase. These developments happened against the backdrop of slower trend growth in post-unification Germany than prior to the reunification. The data tell a tale of two different countries, one that existed in the West prior to reunification, and post-unification Germany. ${ }^{69}$ Future work has to augment our purely descriptive analysis with theory in order to investigate the determinants of these joint inequality and growth trends of the two decades.

\footnotetext{
${ }^{69}$ The authors were lucky enough to experience the German reunification (in the West) during their youth. None of our analysis or discussion is meant to be a critical normative evaluation of this unique historical event or its economic consequences.
} 


\section{References}

[1] Bach, S., G. Corneo and V. Steiner, (2007), "From Bottom to Top: The Entire Distribution of Market Income in Germany, 1992-2001," Working Paper.

[2] Bayer, C. and F. Juessen (2009), "The Life Cycle and the Business Cycle of Wage Risk: A Cross-Country Comparison," mimeo.

[3] Becker, I. J. Frick, M. Grabka, R. Hauser, P. Krause and G. Wagner, (2003), "A Comparison of the Main Household Income Surveys for Germany: EVS and SOEP," in Hauser, R. and I. Becker (eds.) Reporting on Income Distribution and Poverty Perspectives from a German and a European Point of View, Springer Verlag, Heidelberg, p. 55-90.

[4] Biewen, M. (2000), "Income Inequality in Germany During the 1980s and 1990s," Review of Income and Wealth, 46, 1-19.

[5] Biewen, M. (2001), "Measuring the Effects of Socio-Economic Variables on the Income Distribution: An Application to the East German Transition Process," Review of Economics and Statistics, 83, 185-190.

[6] Biewen, M. (2005), "The Covariance Structure of East and West German Incomes and its Implications for the Persistence of Poverty and Inequality," German Economic Review, 6, 445-469.

[7] Bundesministerium für Verkehr, Bau und Städteentwicklung, (2007), Strategien zur Stärkung des Tourismus in den neuen Bundesländern unter Berücksichtigung der Nationalen und Internationalen Wettbewerbssituation, BBR Online Publikation Nr 20/2007.

[8] Deaton, A. and C. Paxson (1994): "Intertemporal Choice and Inequality," Journal of Political Economy, 102, 384-94.

[9] Dustmann, C., J. Ludsteck and U. Schönberg (2007), "Revisiting the German Wage Structure," Working Paper.

[10] Frick, J. and M. Grabka (2008), "Schrumpfende Mittelschicht - Anzeichen einer Dauerhaften Polarisierung der verfügbaren Einkommen?," DIW Wochenbericht 10/2008, 101-108. 
[11] Fuchs-Schündeln, N. and M. Schündeln (2005), "Precautionary Savings and Self-Selection: Evidence from the German Reunification 'Experiment'," Quarterly Journal of Economics, 120(3), 1085-1121.

[12] Fuchs-Schündeln, N. and M. Schündeln (2009), "Who Stays, Who Goes, Who Returns? East-West Migration within Germany since Reunification," Economics of Transition, 17(4).

[13] Giersch, H. K. Paque and H. Schmieding (1992), The Fading Miracle: Four Decades of Market Economy in Germany, Cambridge University Press, Cambridge.

[14] Grabka, M. and J. Frick (2008), "Schrumpfende Mittelschicht - Anzeichen einer dauerhaften Polarisierung der verfügbaren Einkommen?," DIW Wochenbericht Nr. 10/2008, 101-108.

[15] Guvenen, F. (2007), "Learning your Earning: Are Labor Income Shocks Really Very Persistent?" American Economic Review, 97, 687-712.

[16] Hauser, R. and H. Stein (2003), "Inequality of the Distribution of Personal Wealth in Germany, 1973-1998," The Levy Economics Institute Working Paper 398.

[17] Heathcote, J., K. Storesletten and G. Violante (2005), "Two Views of Inequality Over the Life Cycle," Journal of the European Economic Association, 3, 765-775.

[18] Huggett, M., G. Ventura and A. Yaron (2004), "Human Capital and Earnings Distribution Dynamics," Journal of Monetary Economics, 53, 265-290.

[19] Krueger, D., F. Perri, L. Pistaferri and G. Violante (2008), "CrossSectional Facts for Macroeconomists," Working Paper.

[20] Meghir, C. and L. Pistaferri (2004), "Income Variance Dynamics and Heterogeneity," Econometrica, 72, 1-32.

[21] Schwarze, J. (1996), "How Income Inequality Changed in Germany Following Reunification: An Empirical Analysis using Decomposable Inequality Measures," Review of Income and Wealth, 42, 1-11. 
[22] Schwarze, J. (1995), "Simulating German Income and Social Security Payments using the GSOEP," Cross-National Studies in Aging Program Project Paper No. 19, Syracuse University, New York.

[23] Sinn, G. and H. Sinn (1992), Kaltstart. Volkswirtschaftliche Aspekte der deutschen Vereinigung, 2. Auflage, Mohr Siebeck, Tübingen.

[24] Sommer, M. (2008), "Imputation and Harmonization of Income, Consumption, Savings and Wealth Data from the German Income and Expenditure Survey," Working paper, University of Mannheim.

[25] Storesletten, K. C. Telmer and A. Yaron (2004), "Consumption and Risk Sharing over the Life Cycle," Journal of Monetary Economics, 2004, 51, $609-633$ 


\section{A Details of Data Construction: GSOEP}

\section{A.1 Sample Setup and Variable Definition}

\section{A.1.1 Variable Definitions}

All income and hours variables in GSOEP refer to the previous year. ${ }^{70}$ Since we have data from the questionnaires of 1984 to 2005, we therefore have information on income and hours from 1983 to 2004, except for disposable household income. ${ }^{71}$ When we use other household characteristics in our analysis (e.g. when calculating equivalized income, or residual income), we use the characteristics of the current year. ${ }^{72}$ Most of these characteristics (e.g. gender, residence in East/West, education) should be relatively time-invariant, while clearly some others, especially household composition, change more frequently over time. The alternative procedure to use household characteristics from the previous year would however lead to non-random attrition and the loss of a significant number of observations (especially all observations in the year of first interview). The first data on East Germans relate to 1991, except for participation and hours, for which they relate to 1990 . For all calculations, we use cross-sectional weights. All monetary variables are inflated to year 2000 Euros using the consumer price index. ${ }^{73}$

Labor earnings, private transfers, public transfers, and tax payments All income variables are defined as specified by the joint guidelines. The only notable exception comes with self-employment income: Since the question concerning income from self-employment and free-lance work comes in a list of questions regarding labor earnings from different sources, and since the Cross-National Equivalence Files (CNEF) count this variable in its entirety as labor earnings, we choose to follow $\mathrm{CNEF}$ and add this income in its entirety to labor earnings. Thus, there is no capital income from businesses in our definition.

While earnings, private inter-vivo transfers and public transfers are directly reported in GSOEP, tax payments are not reported and are simulated

\footnotetext{
${ }^{70}$ Only participation rates rely on a variable that refers to the current year.

${ }^{71}$ Asset income information is available for the first time for 1984 .

${ }^{72}$ Becker et al. (2002) and Grabka and Frick (2008) also use this procedure.

${ }^{73}$ The consumer price index is different for East and West German states until 1999, and common from 2000 on.
} 
in the CNEF data. The simulation program is fairly comprehensive, updated annually to reflect changes in the tax code, and comprises taxes and social security contributions. ${ }^{74}$ Yet, it is likely that the simulation overstates actual tax payments, since it only takes account of standard deductions (Becker et. al., 2002).

Asset income Asset income is only available in GSOEP from the year 1984 on. The basis of our asset income variables are the CNEF variable for asset income and the CNEF variable for imputed rental value of owner-occupied housing.

The CNEF variable on asset income summarizes financial income (income from stocks and interests on bonds, saving accounts, etc.), adds to this rental income, and subtracts operating costs of non-owner occupied housing. We modify this variable in three ways to comply closer with the guidelines. First, since the guidelines do not call for the subtraction of operating costs, we add this component again. Second, from 1997 on, GSOEP provides a measure of payments made to pay back consumer debt. We assume that $10 \%$ of these payments constitute interest, and subtract these from the CNEF asset income variable. Third, we impute interest payments on mortgages of non-owner occupied housing from information on mortgage payments on these properties, and deduct these interest payments from the asset income variable. ${ }^{75}$ Given that we define all income from self-employment as labor income, no capital income from businesses is added.

The CNEF variable of the imputed rental value of owner-occupied housing also captures the imputed rent subsidy for households living in rent-reduced apartments. It subtracts owner-specific costs for taxation, maintenance, operating costs, and interest on mortgages from the gross imputed rental value. Since the imputed operating costs are not given separately, we do not add them back here as we do for non-owner occupied housing.

Hours and participation Annual hours are provided in the CNEF based on the answers of "hours in a usual week" spent in full-time employment and part-time employment, and the indicated number of months the individual worked full-time or part-time. Thus, vacation, sick-times, holidays etc. are not accounted for. This should certainly lead to an upward bias in the mean

\footnotetext{
${ }^{74}$ For more details, see Schwarze (1995).

${ }^{75}$ See Fuchs-Schündeln and Schündeln (2005) for a detailed description of this procedure.
} 
working hours. Moreover, vacation time has gone slightly up and sick time down in Germany over our sample period. We define anyone as working who reports positive hours in a given year.

To analyze the fraction of the population working full-time or part-time, we use a self-reported categorization as working full-time or part-time. ${ }^{76}$

Wages Wages are calculated by dividing individual labor earnings through hours worked. Both earnings and hours are set to zero if they are missing, but the respective other variable is either missing as well or zero, and the individual reports not to be working. Given that hours worked are overestimated, wages are underestimated. We set wages to missing if an individual reports positive hours but zero earnings, or the other way round.

Head and spouse We follow the guidelines regarding the definition of the head. Specifically, we use the following algorithm:

1. Single households:

(a) If only 1 household member he/she is head.

(b) If only 1 adult household member, this adult member is head.

2. Couple households: identified by the fact that there is exactly one "head" as defined by SOEP and one "partner" as defined by SOEP: for these households, the male who is either defined as head or partner by SOEP is the head. Moreover, the female who is either defined as head or partner by SOEP is the spouse.

3. Non-couple households: Check whether male aged between 25 and 60 is present:

(a) if yes, oldest of these males is head

(b) If no, oldest female aged between 25 and 60 is head

\footnotetext{
${ }^{76}$ Results do not change significantly if we instead characterize individuals as working part-time if they work up to 30 hours a week, and as working full-time if they work more than 30 hours. The fifth percentile of the individuals who categorize themselves as working full-time works 35 hours in a usual week. The 75th percentile of the individuals who categorize themselves as working part-time works 30 hours in a usual week.
} 
Household composition and education We construct the OECD equivalence scales as suggested by the guidelines. As controls for household composition, we construct 9 dummies for each combination of households with 1,2 , and $3+$ adults, and with 0,1 , and $2+$ children. In accordance with the OECD equivalence scales, a child is defined as an individual up to including age 16, and an adult is defined as an individual 17 or older. We define the highest education level of an individual as either college, vocational training, school degree, or no school degree. Any school degree (i.e. Hauptschulabschluss, Realschulabschluss, or Abitur) counts as school degree. As educational controls in regressions of household variables, we construct 20 dummy variables. 4 dummy variables concern the highest degree of the head if no spouse is present in the household. The other 16 dummy variables are all possible combinations of the 4 degrees of education for head and spouse. ${ }^{77}$

\section{A.1.2 Sample selection}

The original sample consists of 181,873 household-year observations. By restricting the sample to household-year observations with heads between the ages of 25 and 60 (including), we are left with 128,398 observations. Excluding the households in which any working household member reports a wage below 3 Euro (in year 2000 Euros), we get a sample of 118,792 household-year observations. Income is not reported for households from the East sample for the years 1989 and 1990. Deleting these observations gives a sample of 115,562 household-year observations. We also delete all household-year observations for which the income variables are missing or reported postgovernment income is negative. This leaves us with 103,316 household year observations for income variables. ${ }^{78}$ In our analyses, we include all subsamples of GSOEP with the appropriate cross-sectional weights. ${ }^{79}$ The only subsample which we exclude is the high income sample, which was added in 2002. This removes 2,520 household-year observations. Thus, the final sample consists of 100,796 household-year observations, of which 71,752 have

\footnotetext{
${ }^{77}$ In the final sample, there are 3,743 household-year observations with missing education.

${ }^{78}$ There are 575 observations for which the household income variables are missing for the head, but are reported for other members of the household. We decided to exclude these households as well. The missing income observations come from all subsamples, all years, and all ages.

${ }^{79}$ Survey weights are very important, since GSOEP oversamples foreigners, immigrants, and East Germans.
} 
a spouse present. Of these household-year observations, 6,274 report zero household earnings, and 5,091 report zero pre-government income.

When analyzing hours worked, we do not exclude households with missing income information. Non-working individuals are always excluded in the analysis of working hours.

\section{A.2 East and West residence before reunification}

In 2003, GSOEP asked respondents whether they lived in East Germany, West Germany, or abroad in 1989. Thus, we can identify whether an individual is originally from the East or originally from the West. $2.75 \%$ of our sample heads lived abroad in $1989,{ }^{80}$ and are excluded from the analysis when we analyze income developments of East and West Germans separately. 2,883 of the sample respondents refuse to answer the question. Of those, we assign 483 to East and 1,890 to West according to their education. GSOEP reports educational degrees from East and West Germany separately, which allows this assignment. The remaining 510 are dropped. ${ }^{81}$ We use this East-West characterization when creating residual variances, but use the current residence in the decomposition analysis of Section 7, to make results comparable to the EVS.

\section{B Details of Data Construction: EVS}

\section{B.1 Sample Setup and Variable Definition}

\section{B.1.1 Variable Definitions}

All income and consumption variables are calculated in annual terms of the same year. Both variables are determined by means of a household diary. The time-frame over which the diary is kept has changed over the years. Specifically, the diary used to be an annual diary until 1993 and has been switched to a quarterly one since the 1998 cross-section. ${ }^{82}$ The conversion into annual figures is done by simple projections. The switch from annual to

\footnotetext{
${ }^{80}$ Most of these are from the immigrant sample.

${ }^{81}$ There are 6 individuals who report living in East Germany in 1989, but have been in the sample before 1990. We drop these observations.

${ }^{82}$ Selected items were recorded over one month in the early surveys (1978-1993).
} 
quarterly data may nevertheless have distorting effects on the distributions of income and consumption as the cross-quarter correlations are unknown. ${ }^{83}$

The wealth variables are constructed from a set of questions on a variety of different individual assets. Again, the actual questionnaire has changed over the years as certain asset categories have been regrouped. In all crosssections, the wealth questions refer to the wealth position at the beginning of the same year. ${ }^{84}$

Finally, all household characteristics are questioned at the beginning of the year and refer to the same year. We report all monetary variables in Euros and prices of 2001. To do so, we use separate CPIs for East and West Germany. All results are weighted using the sample weights provided by the Federal Statistical Office.

Labor income, private transfers, public transfers, and tax payments All income variables are defined as close as possible to the joint guidelines. Like for the GSOEP, we deviate from the guidelines only for the case of income from self-employment. We have no information which would allow us to separate labor and capital income from businesses so that we include all income from self-employment into labor income.

Labor income is thus defined as the sum of individual payments from dependent and self-employed work, which are mostly questioned separately for each household member in the EVS. Private transfers comprise private pensions and private non-pension transfers. Among private pensions we include all kinds of occupational pensions and private annuities. The other - nonpension - private transfers cover support payments from unions, any kinds of non-government organizations and other private households. Furthermore, payments from insurance companies other than pensions are included and finally inheritances.

Public transfers include all kinds of public pensions, health related transfers like sickness benefits, unemployment benefits and other transfers like

\footnotetext{
${ }^{83} \mathrm{~A}$ more comprehensive discussion of these issues is provided in Sommer (2008).

${ }^{84}$ The timing of the questions has been altered repeatedly though: Between 1978 and 1988, the wealth questions were split into an introductory interview (financial wealth) and a final interview (real estate and debt) at the beginning and at the end of the year respectively. In 1993, the wealth questions were regrouped into the final interview. In 1998, the wealth questions were added to the quarterly household diary and finally in 2003, they moved into an appendix to the introductory interview. To what extent this induces differences in the quality of the data is unclear.
} 
child benefits and housing benefits. ${ }^{85}$

Tax payments are - in contrast to the GSOEP - also questioned in considerable detail in the EVS. They comprise ordinary income taxes and contributions to the social security system, as well as estate, gift, wealth, and church taxes. Also selected consumption related taxes are included like animal taxes and taxes for hunting rights. Finally, we account for tax refunds which we treat like negative taxes.

Financial asset income is defined as the sum of interest and dividend payments from financial wealth. Adding actual rental income and hypothetical rent for owner occupied housing net of interest payments for outstanding mortgages we arrive at total asset income. For part of consumer credits, an analog procedure is hampered as the data does not distinguish between interest payments and credit repayments. As all business income is included in income from self-employment, a possible capital income component is equivalently not included in asset income.

Our definition of pre-government income adds income from employment, private transfers, and asset income from financial assets. To arrive at postgovernment income, we add all kinds of public transfers and deduct taxes and contributions to the social security system. Note, that the definitions of pre- and post-government income do not include income from real estate wealth.

Consumption We employ two different definitions of non-durable consumption in our analyses. They differ in the inclusion of housing expenditures (rented and owner-occupied) and are otherwise identical. As consumption is captured in much detail in the EVS we can construct an almost ideal measure of non-durable consumption. Where we have to deviate from the desired classification of expenditures into durable and non-durable consumption it is due to changes in the questionnaire. Homogeneous definitions across years seem more important for our analyses than improving the definitions in individual years.

We include expenditures for food, clothes, energy, health, body care, travel, communication, education, rent, and household services in non-durable consumption. On the other side, we declare expenditures for furniture and real estate maintenance durable consumption only.

\footnotetext{
${ }^{85} \mathrm{~A}$ complete list of items included in the income and wealth variables can be found in the appendix of Sommer (2008).
} 
The remaining categories leisure, vehicles, and miscellaneous are part durable and part non-durable. Where possible we split the categories accordingly. In case of doubt or indivisibilities we include the expenditures into durable consumption as a clean measure of non-durable consumption seems more important to us. Notable among the remaining expenditures which we classify as non-durable are car repairs and repairs of all kinds of electronic devices as well as tickets for all kinds of entertainment. Finally, we include insurance premia and expenditures for financial services in nondurable consumption.

Wealth We define gross financial wealth as the sum of assets held with banks, in building society saving contracts, and in securities. Assets held with banks mostly include saving accounts, saving certificates, and term deposits. The securities include stocks, government and commercial bonds, as well as mutual funds. Note that also mutual funds on housing assets are included. Further, we add the surrender value of life insurance wealth. The EVS cross-sections 1998 and 2003 additionally include privately lent out money, and for 1993 we have additional information on checking account balances. We include neither in our definition of financial wealth for reasons of comparability. For a comprehensive measure of financial wealth we are also lacking cash holdings, which the EVS like most other surveys has never questioned. Deducting outstanding consumer credits we arrive at our definition of net financial wealth.

A comprehensive definition of real wealth would include housing and business equity, as well as valuables and durable goods. For reasons of data availability we restrict our definition of real wealth to housing equity. Especially the lack of business equity will have effects on evaluations of wealth inequality as it likely accounts for a large share of private wealth among business owners. Unfortunately, the EVS only included questions on business wealth in the year 1983 and referred to fiscal values instead of market values. For part of valuables some data are available on purchases and sales. We also know about the existence and number of certain durable goods, e.g. cars, fridges or dishwashers, but no information about their value is included.

As mentioned above, we therefore define gross real wealth to be the market value of all pieces of real estate owned by the household. To arrive at net real wealth, we deduct the amount of outstanding mortgages. 
The household head We proceed according to the following algorithm:

- For all single households, households with only one adult member, as well as couple households the oldest male becomes the new household head. Where there is no male in the household, the oldest female is defined the household head

- Only for composite households, we employ a different definition and choose the oldest working male to be the household head. A decision had to be made on the question who should be considered working:

- We start out from the individuals' self-assessed work-status as provided in the EVS data

- For individuals who declare themselves as "non-working" or "retired" but nevertheless indicate positive amounts of work income, we override their self-assessment. ${ }^{86}$

Family composition and education For the cross-sectional variance decomposition, we include dummies for nine household types. The ten underlying household types are defined based on the number of adults and the number of children in the household. Specifically, we distinguish:

Type 1: 1 adult, no kids

Type 2: 1 adult, 1 kid

Type 3: 1 adult, 2 or more kids

Type 4: 2 adults, no kids

Type 5: 2 adults, 1 kid

Type 6: 2 adults, 2 kids

Type 7: 2 adults, 3 or more kids

Type 8: 3 or more adults, no kids

Type 9: 3 or more adults, 1 kid

Type 10: 3 or more adults, 2 or more kids

Additionally, we include dummies for different educational attainments, which always refer to the household head. The EVS does not provide information on the individuals' years of school or the highest school degrees.

\footnotetext{
${ }^{86}$ We apply this correction only for the first two household members as the early crosssections 1978-88 do not report individual level incomes from work for the remaining household members.
} 
Instead, since 1993, individuals are asked about their job specific education. After some harmonization we distinguish the following types of education:

Type 1: no job specific education or training (yet), also students and interns

Type 2: college degree

Type 3: degree from a College of Applied Science (FH)

Type 4: master craftsman

Type 5: junior craftsman

\section{B.1.2 Sample selection}

The six scientific use files of the EVS which span the years 1978 through 2003 in five-year intervals contain roughly 40-50,000 households each. Of the total 267,434 observations we drop those with a head aged below 25 or above 60 . This leaves us with a sample of 192,429 households. We furthermore drop 46 households with extremely high incomes. This is necessary, as the Federal Statistical Office applies a sampling threshold with respect to household income. This threshold, however, has changed over the years so that a different slice of the income distribution is cut off every year. We aim to eliminate the effects of the changing sampling threshold by applying the lowest threshold which was in place in 1988, to all other years.

For the cohort-analysis underlying the life-cycle profiles, we additionally excluded East Germans, which were not sampled until 1993. Again, the purpose is to ensure the homogeneity of cohorts as good as possible. Given that we only know the place of residence from the EVS and not the regional provenance from the years before the German Reunification, the correction is obviously a poor one but the best we can do. After excluding these subsamples, we are left with 22-33,000 households per year and a total of 172,628 observations.

Contrary to the GSOEP approach, we do not exclude households with implausibly low wages as the EVS does not contain direct information on wages and questions weekly hours only since 2003. Any further exclusions apply only for technical reasons. Especially calculating the variance of logs, for instance, we lose all observations with zero or negative values of income. 